\title{
TU/e EmonOWEN

\section{A nonlinear rate-dependent model for predicting the depth of penetration in ultra-high performance fiber reinforced concrete (UHPFRC)}

\author{
Citation for published version (APA): \\ Cao, Y. Y. Y., Tan, Q. H., Jiang, Z. G., Brouwers, J., \& Yu, Q. (2020). A nonlinear rate-dependent model for \\ predicting the depth of penetration in ultra-high performance fiber reinforced concrete (UHPFRC). Cement \& \\ Concrete Composites, 106, [103451]. https://doi.org/10.1016/j.cemconcomp.2019.103451
}

\section{Document license: \\ TAVERNE}

DOI:

10.1016/j.cemconcomp.2019.103451

Document status and date:

Published: 01/02/2020

\section{Document Version:}

Publisher's PDF, also known as Version of Record (includes final page, issue and volume numbers)

\section{Please check the document version of this publication:}

- A submitted manuscript is the version of the article upon submission and before peer-review. There can be important differences between the submitted version and the official published version of record. People interested in the research are advised to contact the author for the final version of the publication, or visit the DOI to the publisher's website.

- The final author version and the galley proof are versions of the publication after peer review.

- The final published version features the final layout of the paper including the volume, issue and page numbers.

Link to publication

\footnotetext{
General rights

- You may freely distribute the URL identifying the publication in the public portal. follow below link for the End User Agreement:

www.tue.nl/taverne

Take down policy

If you believe that this document breaches copyright please contact us at:

openaccess@tue.nl

providing details and we will investigate your claim.
}

Copyright and moral rights for the publications made accessible in the public portal are retained by the authors and/or other copyright owners and it is a condition of accessing publications that users recognise and abide by the legal requirements associated with these rights.

- Users may download and print one copy of any publication from the public portal for the purpose of private study or research.

- You may not further distribute the material or use it for any profit-making activity or commercial gain

If the publication is distributed under the terms of Article $25 \mathrm{fa}$ of the Dutch Copyright Act, indicated by the "Taverne" license above, please 


\title{
A nonlinear rate-dependent model for predicting the depth of penetration in ultra-high performance fiber reinforced concrete (UHPFRC)
}

\author{
Y.Y.Y. Cao ${ }^{\text {a }}$, Q.H. Tan ${ }^{\text {c }}$, Z.G. Jiang ${ }^{\text {d }}$, H.J.H. Brouwers ${ }^{\text {a }}$, Q.L. Yu ${ }^{\text {a,b, * }}$ \\ ${ }^{\text {a }}$ Department of the Built Environment, Eindhoven University of Technology, P.O. Box 513, 5600 MB, Eindhoven, the Netherlands \\ ${ }^{\mathrm{b}}$ School of Civil Engineering, Wuhan University, 430072, Wuhan, PR China \\ ${ }^{\mathrm{c}}$ College of Aerospace Science and Engineering, National University of Defense Technology, Changsha, Hunan, 410073, PR China \\ d Undergraduate School, National University of Defense Technology, Changsha, Hunan, 410073, PR China
}

\section{A R T I C L E I N F O}

\section{Keywords:}

Ultra-high performance fiber reinforced

concrete (UHPFRC)

Cavity expansion model

Hoek-Brown criterion

Depth of penetration

Rate effect

\begin{abstract}
A B S T R A C T
Ultra-high performance fiber reinforced concrete (UHPFRC) is increasingly utilized in protective structures because of its ultra-high compressive strength and excellent toughness. Nevertheless, there is still a lack of model for predicting the depth of penetration (DOP) in UHPFRC against projectile penetrations. This study proposes an analytical predicting model for UHPFRC on the basis of the dynamic cavity expansion theory. The Hoek-Brown criterion is utilized to account for the nonlinear response of UHPFRC, and its rate dependency is also addressed in the model. The developed predicting model is validated against penetration experimental data, and its effectiveness is further compared with previous predicting formulae. The comparison results indicate that the proposed model can achieve more reasonable DOP predictions in UHPFRC targets. Finally, a number of influential parameters are discussed based on the proposed model. It is observed that the DOP is affected by the target compressive strength, while the tensile strength influences the cracked region radius. The developed DOP predicting model provides an accurate estimation of the UHPFRC impact resistance and promotes an effective approach to design UHPFRC protective structures.
\end{abstract}

\section{Introduction}

The penetration resistance of protective structures can be a critical security consideration. These structures have a high risk of being exposed to projectiles and ballistic weapons in conflict areas or under terrorist attacks. Ultra-high performance fiber reinforced concrete (UHPFRC) is generally characterized by its ultra-high compressive strength, excellent energy absorption capacity and outstanding damage tolerance [1-3], which makes it a potential solution for improving the resistant capacities of protective structures [4-7]. The advantageous impact resistance of UHPFRC has been revealed by various studies. Yu et al. $[6,8]$ evaluated the performances of a sustainable UHPFRC against projectile and claimed that the developed UHPFRC with hybrid fibers is a good choice for protective structures. Maca et al. [9] and Sovjak et al. $[10,11]$ investigated the responses of UHPFRC under deformable and non-deformable projectile impacts; their studies presented that UHPFRC provides a better protection compared to high-strength concrete and UHPFRC containing $2 \%$ of fibers achieves an optimal resistance. Liu et al. $[12,13]$ experimentally and numerically evaluated the penetration responses of UHPFRC, and observed the superior performances of UHPFRC in terms of the depth of penetration (DOP), the crater diameter as well as the projectile abrasion.

Predicting the DOP in UHPFRC is essential for designing protective structures. A number of DOP predicting models have been proposed for concrete material $[8,14]$, and detailed reviews can be found in [15-17]. These models provide straightforward approaches to predict the DOP in concrete with the considerations of the impact velocity, concrete strength, projectile weight and geometry [18]. Generally, the current DOP prediction models can be classified into empirical, semi-empirical and theoretical categories. The application range of empirical models often depends on the conducted experiments, from which the formulae are derived by data-fitting. Additionally, empirical models such as ACE, NDRC and UKAEA formulae are usually unit dependent, making it difficult to identify the important physical quantities in the formulae [14]. Semi-empirical models are in general developed based on theoretical analysis with some parameters determined by experimental data, for example the empirical constant $S$ in the Forrestal semi-empirical formula [14,19] and Li-Chen formula [15]. It should be noted that these empirical and semi-empirical models are mainly proposed for

\footnotetext{
* Corresponding author. Department of the Built Environment Eindhoven University of Technology P.O. Box 513, 5600 MB, Eindhoven, the Netherlands.

E-mail address: q.yu@bwk.tue.nl (Q.L. Yu).
} 


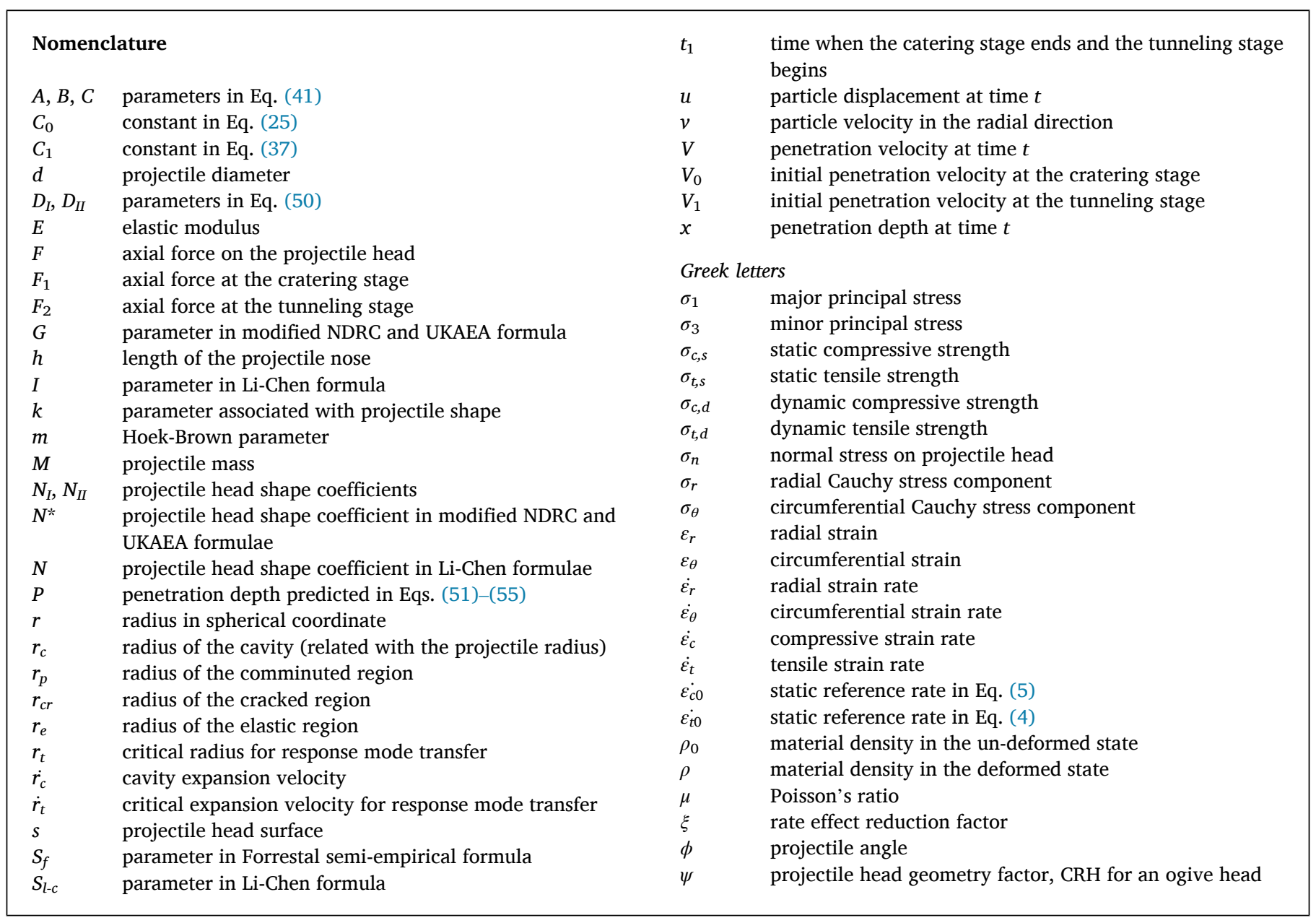

normal strength concrete (NC), i.e. some parameters in the models are obtained based on the properties of NC, and using them to predict the DOP in UHPFRC would lead to inaccurate results [18]. With regard to theoretical models, they calculate the impact resisting force with some physically based assumptions, e.g. the resistance on the projectile is constant [20] or velocity dependent $[19,21]$, and then derive the DOP through the Newton's second law with the analytical resisting force [20]. Among the existing theoretical models, the cavity expansion theory analytically calculates the resistance with definite physical meanings, and it has been successfully applied for concrete targets impacted by different projectiles under various penetration velocities [22-25].

Impact cratering, penetration tunneling with spherical radiation crack and the rear surface plugging or spalling are the dominant phenomena in a cementitious target under ballistic impacts $[8,26,27]$. The related mechanisms are quite complex, including wave propagation and reflection, concrete cracking and comminution, and phase change in the target [23]. The cavity expansion theory is usually used for the tunneling stage, the main characteristic of which can be described by the theory. For example, the concrete spherical radiation cracking and material comminution, which are observed in experimental and numerical studies [27], are reflected by the theoretical response regions surrounding the cavity and described by the material constitutive relations or the yield criteria. Applying the cavity expansion theory, the penetration of the projectile in a target at the penetration tunneling stage is modeled as the expansion of a spherical or cylindrical cavity at a constant velocity. The resistant pressure on the projectile is then computed analytically by the radial stress at the cavity surface [28]. Compared to the cylindrical cavity expansion theory, which is reported to overestimate the projectile's early deceleration response and underestimate its later response [29], the spherical cavity expansion theory gives more accurate results as long as proper yield criteria of the target material are adopted [24]. For instance, Forrestal et al. [21,30] utilized the spherical cavity expansion theory to approximate the target response; a nearly identical agreement was obtained between their results and the finite-element simulations, showing the validity of the spherical cavity expansion theory.

To simplify the calculation, linear yield criteria, e.g. the MohrCoulomb criterion [22,31,32] and the Drucker-Prager criterion [23], are usually applied in the current cavity expansion theory [33,34]. For instance, Forrestal and Tzou [22] developed a spherical cavity expansion model for concrete targets with the assumption that the material surrounding the projectile yields according to the Mohr-Coulomb criterion with a tension cutoff. Feng et al. [23] used the modified Drucker-Prager Cap plasticity criterion to describe the concrete behavior in their dynamic cavity expansion model, which was validated by the penetration test data of NC targets with strengths of $36 \mathrm{MPa}$ and $51 \mathrm{MPa}$. Nevertheless, for an UHPFRC target under high speed penetrations, its constitutive relation exhibits nonlinear characteristics due to the extremely high pressure around the projectile-target interface [33,34]. As a consequence, nonlinear yield criteria, such as the Hoek-Brown criterion and the Griffith criterion, can be more appropriate than their linear counterparts when applying the cavity expansion theory for UHPFRC [33,34]. Few relevant research can be found in the available literature utilizing nonlinear yield criteria in cavity expansion models. Among the limited studies, Meng et al. [24] established a finite cavity expansion model based on the modified Griffith criterion; Kong et al. $[33,34]$ introduced a hyperbolic yield criterion and Murnaghan equation of state (EOS) to describe the plastic response of concrete. It should 
be pointed out that the former study focuses on NC targets confined in steel tubes, i.e. the boundary conditions in the model cannot be applied for common UHPFRC targets without confinement; whereas the latter one has complex EOS with many parameters determined by complicated experiments such as triaxial compression tests and flyer-plate-impact tests [33,34].

In addition, most of the current cavity expansion models do not take the rate dependency of the concrete material into account. However, at a high penetration velocity, the projectile produces very high strain rates in the surrounding concrete and the rate effects of the concrete material can considerably affect the penetration resistance since the compressive and tensile strengths are enhanced [35] and the fiber pullout force and energy are also improved [36]. Forrestal et al. [19,21,22] conducted a series of investigations on the cavity expansion model for various materials. The strain rate effect was presented in their models for the aluminum target [21], but it was ignored in the models for concrete material [22]. More recently, Feng et al. [23] incorporated the concrete rate dependency into the Drucker-Prager criterion. The penetration resistances from cavity expansion models with and without considering the rate effects were compared in their study, and the results suggested that the resistance is underestimated in the case without rate effects, especially under high speed penetration. This, therefore, indicates the significance of catering for the rate dependency of concrete in the dynamic cavity expansion model.

In the present study, a new DOP predicting model for UHPFRC is proposed on the basis of an improved dynamic spherical cavity expansion theory with the nonlinear failure and rate effects of UHPFRC accounted. In Section 2, the Hoek-Brown criterion [37] is introduced in the model to describe the nonlinear response of UHPFRC material, and the rate effects under projectile penetration are considered to present the enhancement of the UHPFRC resistance. Section 3 analyzes the response modes of the semi-infinite UHPFRC target with the improved dynamic spherical cavity expansion theory. The obtained cavity surface stress is then applied in the DOP predicting formula in Section 4. In Section 5, the proposed model is compared with the experimental data and the previous predicting formulae, and effects of the concrete strengths and the reduction factor are analyzed as well.

\section{Improved constitutive model for UHPFRC}

\subsection{Hoek-Brown criterion}

The Hoek-Brown criterion is initially introduced to describe the failure of hard rocks under confining pressures, and it has been widely used for the design of underground excavations [37]. The non-linear parabolic form distinguishes the Hoek-Brown criterion from linear failure criteria, e.g. the Mohr-Coulomb criterion [38]. Similar to the underground rocks with the confining pressure, in a UHPFRC target, the inner UHPFRC surrounding a projectile is also under high confinement generated by the outer UHPFRC layer due to the lateral inertia at high strain rates [15]. Considering this, the Hoek-Brown criterion is applied in the cavity expansion model for UHPFRC in this study.

The expression of the Hoek-Brown criterion is given as [37]:

$\begin{array}{ccc}\sigma_{1} & \sigma_{3} & \sigma_{c, s} / m \frac{\sigma_{3}}{\sigma_{c, s}}\end{array}$

where $\sigma_{c, s}$ is the static compressive strength; $\sigma_{1}$ and $\sigma_{3}$ are the major and minor principal stresses, respectively; $m$ is a parameter related to material properties. It is suggested that $m$ is affected by the ratio of compressive to tensile strengths as well as the friction coefficient of the material [24].

The above equation can be transformed to:

$$
\frac{\sigma_{1}}{\sigma_{c, s}}{\frac{\sigma_{3}}{\sigma_{c, s}}}^{2} \quad 1 \quad m \frac{\sigma_{3}}{\sigma_{c, s}}
$$

Since the strength ratio of UHPFRC differs from that of NC, the values of $m$ should also be different. Moreover, UHPFRC with fine aggregates usually has a smaller friction coefficient, as a result, it tends to have a smaller $m$ than NC with coarse aggregates [24]. To obtain the relation between $m$ and $\sigma_{c, s}$, triaxial compression test data of concrete with the strength from around $90 \mathrm{MPa}-170 \mathrm{MPa}$ are collected [39-42]. Fitting the data gives the corresponding values of $m$ to various $\sigma_{c, s}$, as shown in Fig. 1a. The equations in the figure are the expressions of the trend lines of each group of data. An empirical equation to estimate the value of $m$ for UHPFRC with different strength is then proposed from Fig. 1b and expressed as $\left(\sigma_{c, s}\right.$ in $\left.\mathrm{MPa}\right)$ :

$m \quad 23.22 \quad 0.11 \sigma_{c, s}$

\subsection{Rate dependency incorporation}

The target material surrounding a penetrating projectile is under high pressure and high strain rate. As presented in literature [15,43,44], the behavior of the cement based material is considerably affected by the strain rate, and the strengths of concrete exhibit significant improvements under high loading rates. Consequently, the failure criterion of the cement based material differs under impact loadings and it requires modification to address the rate effects in the case of penetration.

Dynamic increase factor (DIF) is commonly used to gauge the strength enhancement. The DIF expressions for concrete recommended in the CEB-FIB Model Code 2010 [35] are most widely accepted, and they are incorporated in the constitutive relation in the present study to account for the rate effects. The expressions are given as Eqs. (4) and (5).

For tensile strength [35]:

$$
\begin{array}{cccc}
\mathrm{DIF}_{t} & \frac{\dot{\varepsilon}_{t}}{\dot{\varepsilon}_{t 0}}{ }^{0.018} \ldots \text { for. } \dot{\varepsilon}_{t} \quad 10 \mathrm{~s}{ }^{1} \\
\mathrm{DIF}_{t} & 0.0062{\frac{\dot{\varepsilon}_{t}}{\dot{\varepsilon}_{t 0}}}^{1 / 3} \ldots \text { for } \dot{\varepsilon}_{t}>10 \mathrm{~s}{ }^{1}
\end{array}
$$

where $\dot{\varepsilon}_{t}$ is the tensile strain rate, the static reference rate $\dot{\varepsilon}_{t 0} \quad 1 \quad 10^{6}$ $\mathrm{s}^{1}$.

For compressive strength [35]:

$$
\begin{array}{ll}
\mathrm{DIF}_{c} & \frac{\dot{\varepsilon}_{c}}{\dot{\varepsilon}_{c 0}}{ }^{0.014} \ldots \text {..for } \dot{\varepsilon}_{c} \quad 30 \mathrm{~s}{ }^{1} \\
\mathrm{DIF}_{c} & 0.012{\frac{\dot{\varepsilon}_{c}}{\dot{\varepsilon}_{c 0}}}^{1 / 3} \text {..for } \dot{\varepsilon}_{c}>30 \mathrm{~s}{ }^{1}
\end{array}
$$

where $\dot{\varepsilon}_{c}$ is the compressive strain rate, the static reference rate $\dot{\varepsilon}_{c 0}$ $3010^{6} \mathrm{~s}^{1}$.

It should be noted that these DIF formulae are developed based on dynamic tests of NC, applying them directly for UHPFRC would overestimate its rate effects under penetrations. On the one hand, the compressive strength enhancement of concrete material at a high strain rate, e.g. at the order of $10^{3}-10^{4} \mathrm{~s}^{1}$, is mainly attributed to the lateral inertia and the lateral confinement [15]. That is to say, the obtained DIF is not a material property and the true strength increase is much less than the prediction in the CEB-FIB Model Code. On the other hand, the DIF of concrete material tends to decrease as its compressive strength increases, i.e. DIF of UHPFRC should be smaller than that of NC [45-47]. Nevertheless, since current DIF formulae for UHPFRC are mainly established with small amounts of data, most studies still utilize the CEB-FIB Model Code to predict the DIFs of UHPFRC [48]. In the present study, these recommended DIF formulae in the CEB-FIB Model Code are also adopted, but the obtained cavity surface stress is then corrected with a reduction factor $\xi$ when applying it in the DOP predicting model (see Section 4). By comparing the literature-given DIFs of UHPFRC [49, 


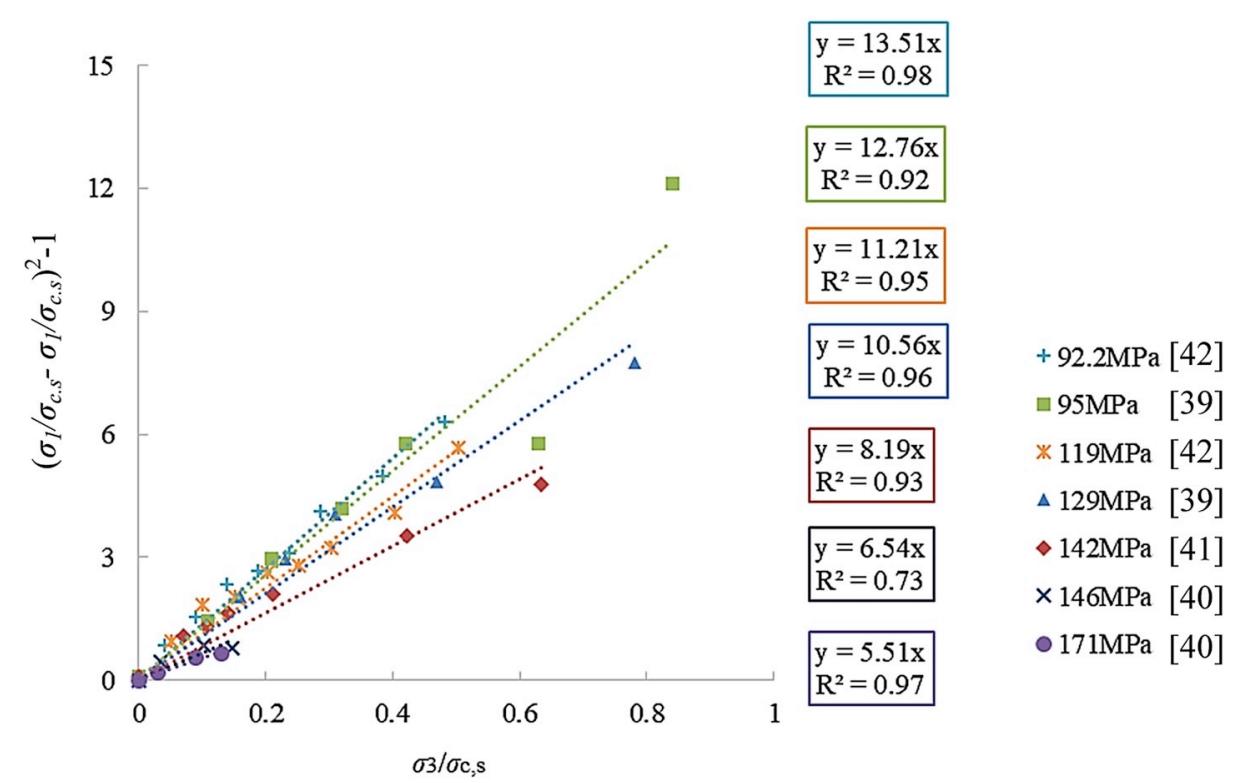

(a) Obtaining $m$ by data fitting

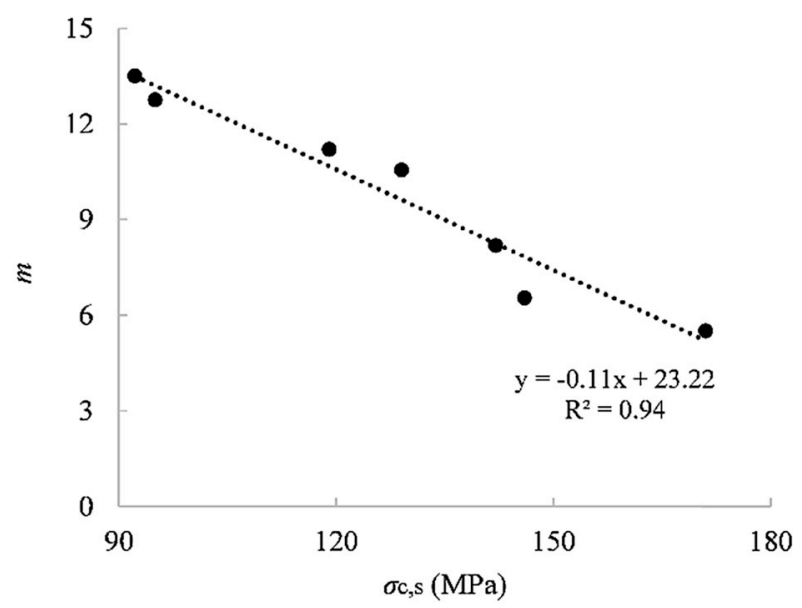

(b) Relationship between $m$ and $\sigma_{c, s}$

Fig. 1. Hoek- Brown parameter $m$.

50] and those given in the CEB-FIB Model Code at strain rates between $10^{3}-10^{4} \mathrm{~s}^{1}, \xi \quad 0.35$ is determined in this study for both compression and tension (an example of rate effects on $\sigma_{c, s}$ is shown in Fig. 2). More discussion on $\xi$ is presented in Section 5.2.3.

\section{Dynamic cavity expansion model}

\subsection{Descriptions}

The following assumptions are proposed in this study for the dynamic cavity expansion model:

The projectile penetration process in a semi-infinite UHPFRC target is treated as a spherical cavity expanding from zero to a radius $r_{c}$ at a constant velocity $\dot{r}_{c}$. Since the cavity is expanded from zero initial radius, a steady-state is immediately reached and the cavity keeps expanding under a constant pressure [51,52]. Consequently, the acceleration term $r_{c}$ and other higher order terms equal to zero. Otherwise, if a cavity is expanded from a finite initial radius (not

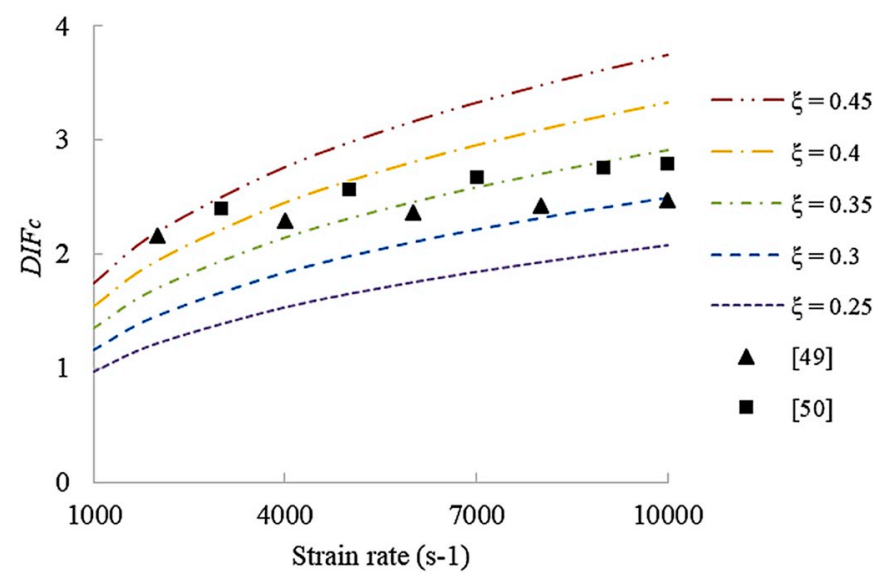

Fig. 2. DIF reduction factor $\xi$. 
considered in the present study), an increasing pressure is required for the continued expansion and the acceleration should be considered [51].

Similar to previous studies concerning NC $[23,24,53]$, the UHPFRC target is assumed to be incompressible to simplify the problem with possible analytical solutions; otherwise complicated approximations are needed, which makes the problem too complex to solve while the improved accuracy can be very limited [30]. The assumption is acceptable since the micro structure of UHPFRC is much denser than that of NC [54,55]. Nevertheless, the negligence of material compressibility may lead to the overestimation of the cavity surface stress to a certain degree [22], and this should be kept in mind in the error analysis of DOP models.

For an incompressible material, no density change occurs during the deformation; and the radial stress, displacement and velocity at the interfaces of different response regions should be continuous according to the Hugoniot interface conditions [21].

In the comminuted region, the UHPFRC material obeys the HoekBrown criterion described in Section 2.1. The principal stress components satisfy the conditions $\sigma_{1} \quad \sigma_{r}, \sigma_{3} \quad \sigma_{\theta}$ in the spherical coordinates [24].

Based on the above assumptions, the schematic diagram of the cavity expansion model is illustrated in Fig. 3. Two possible response modes could be produced in the surrounding material depending on the expansion velocity $\dot{r}_{c}:(1)$ at a relatively small $\dot{r_{c}}$, three response regions are presented in the target, namely a comminuted region $\left(r_{c}<r \quad r_{p}\right)$, a cracked region $\left(r_{p}<r \quad r_{c r}\right)$ and an elastic region $\left(r_{c r}<r \quad r_{e}\right) . r_{c}, r_{p}, r_{c r}$ and $r_{e}$ are radii of the cavity and the above corresponding regions (Fig. 3a); (2) as the expansion velocity $\dot{r}_{c}$ increases and exceeds a critical value $\dot{r}_{t}$, the comminuted region reaches and surpasses the cracked region, viz. $r_{p} \quad r_{c r}$, then the response of the target turns to an elastic-comminuted mode as shown in Fig. $3 \mathrm{~b}$.

\subsection{Elastic-cracked-comminuted response}

The conservation equations of momentum and mass can be expressed as [21]:

$\frac{\partial \sigma_{r}}{\partial r} \quad 2 \frac{\sigma_{r} \quad \sigma_{\theta}}{r} \quad \rho \frac{\partial v}{\partial t} \quad v \frac{\partial v}{\partial r}$

$\rho_{0} \frac{\partial}{\partial r} \quad r \quad u^{3} \quad 3 \rho r^{2}$

where $\sigma_{r}$ and $\sigma_{\theta}$ are the radial and circumferential Cauchy stress components, measured positive in compression; $r$ is the radius; $v$ is the particle velocity in the radial direction at time $t$, and $u$ is the particle displacement (both measured positive outward); $\rho_{0}$ and $\rho$ are the densities in the un-deformed and deformed states. For an incompressible material, $\rho \quad \rho_{0}$ [21].

The steady state expansion assumption leads to the boundary condition that the displacement at the cavity boundary must equal to its radius [51]. Therefore, Eq. (7) can be integrated with $u\left(\begin{array}{lll}r & r_{c}\end{array}\right) r_{c}$ [24], and it yields

$\begin{array}{lllll}u & r^{3} & r_{c}^{3} & \end{array}$

The particle displacement and velocity are related by [21]:

$\frac{\partial u}{\partial t} \quad v \quad 1 \quad \frac{\partial u}{\partial r}$

Eqs. (8) and (9) then result in the expression of $v$ as [21]:

v $\quad \frac{r_{c}}{r}{ }^{2} \dot{r}_{c}$

The strain rates at the radial and the circumferential directions are then obtained as [21]:

$\dot{\varepsilon}_{r} \quad \frac{\partial v}{\partial r} \quad 2 \frac{r_{c}^{2} \dot{r}_{c}}{r^{3}}$

$\dot{\varepsilon}_{\theta} \frac{v}{r} \frac{r_{c}^{2} \dot{r}_{c}}{r^{3}}$

Substituting Eqs. (11) and (12) into Eq. (6) gives the new form of the momentum conservation equation; and letting the acceleration term $r_{c} \quad 0$ leads to:

$\frac{\partial \sigma_{r}}{\partial r} \quad 2 \frac{\sigma_{r} \quad \sigma_{\theta}}{r} \quad 2 \rho \dot{r}_{c}^{2} \quad \frac{r_{c}}{r^{2}} \quad \frac{r_{c}^{4}}{r^{5}}$

\subsubsection{Elastic region}

The response equations in the elastic region are presented in [21]. The particle displacement and velocity are [21]:

$u \frac{r_{c}^{3}}{3 r^{2}}$

$v \quad \frac{r_{c}}{r}{ }^{2} \dot{r}_{c}$

Thus the elastic strains at the radial and the circumferential directions are

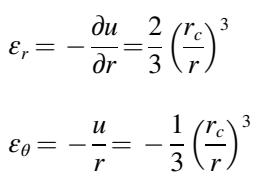

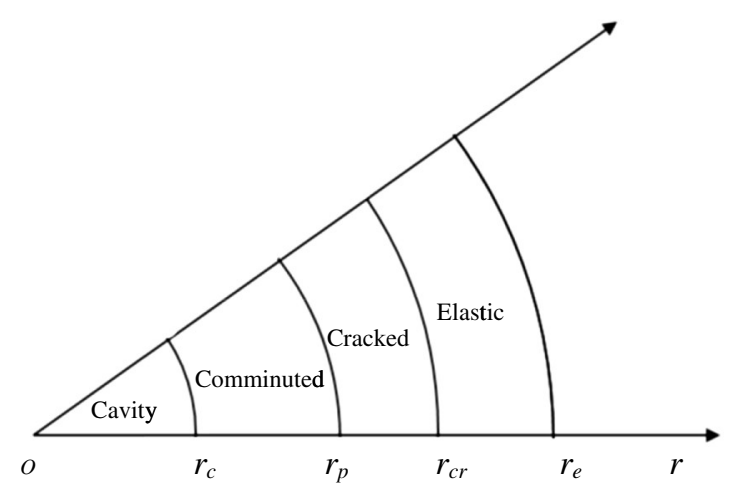

(a) elastic-cracked-comminuted response

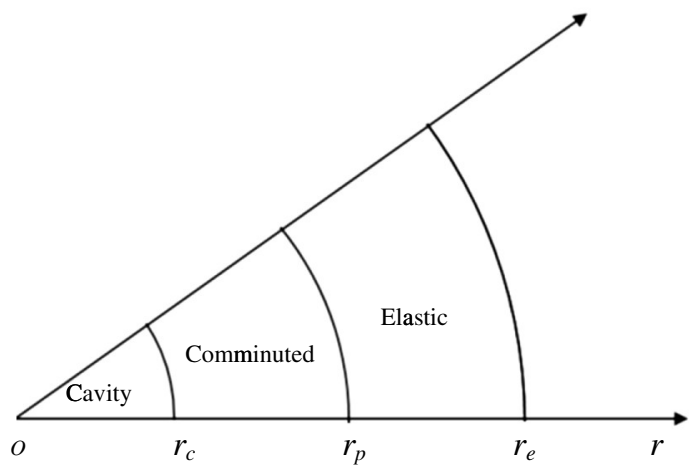

(b) elastic-comminuted response

Fig. 3. Response regions in UHPFRC target. 
The elastic strains and the Hook's law lead to the relation between the elastic stresses:

$\sigma_{r} \quad \sigma_{\theta} \quad \frac{E}{1 \mu} \varepsilon_{r} \quad \varepsilon_{\theta} \quad \frac{E}{1 \mu}{\frac{r_{c}}{r}}^{3}$

where $E$ is the elastic modulus; $\mu$ is the Poisson's ratio and it equals to 0.5 for incompressible materials.

Integration of Eq. (13) with Eq. (18) yields the expressions for the elastic stresses:

$\sigma_{r} \frac{2}{3} \frac{E}{1 \mu}{\frac{r_{c}}{r}}^{3} \quad 2 \rho \dot{r}_{c}^{2} \quad \frac{r_{c}}{r} \quad \frac{1}{4}{\frac{r_{c}}{r}}^{4}$

$\sigma_{\theta} \quad \frac{1}{3} \frac{E}{1 \mu} \frac{r_{c}{ }^{3}}{r} \quad 2 \rho \dot{r}_{c}^{2} \quad \frac{r_{c}}{r} \frac{1}{4}{\frac{r_{c}}{r}}^{4}$

At the elastic-cracked region interface $r \quad r_{c r}$, the circumferential stress reaches the dynamic tensile strength $\sigma_{t, d}$ of the material, viz.

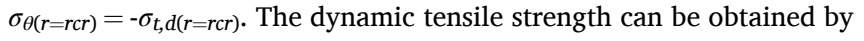

$\begin{array}{lllll}\sigma_{t, d} r & r_{c r} & \mathrm{DIF}_{t r} r_{c r} & \sigma_{t, s}\end{array}$

where $\sigma_{t, s}$ is the static tensile strength of UHPFRC, and DIF ( $\left.r r r r\right)_{r}$ can be calculated by Eq. (4) with

$\begin{array}{llll}\dot{\varepsilon}_{t} & \dot{\varepsilon}_{\theta r} r_{c r} & \frac{r_{c}^{2} \dot{r}_{c}}{r_{c r}{ }^{3}}\end{array}$

By combining Eqs. (20)-(22), one gets the equations to determine the location of the elastic-cracked region interface, viz. $r_{c r}$ :

$2 \rho \dot{r}_{c}^{2} \frac{r_{c}}{r_{c r}} \frac{1}{4}{\frac{r_{c}}{r_{c r}}}^{4} \quad \frac{1}{3} \frac{E}{1 \mu}{\frac{r_{c}}{r_{c r}}}^{3} \quad \sigma_{t, s} \frac{r_{c}{ }^{2} \dot{r}_{c}}{r_{c r}{ }^{3} \dot{\varepsilon}_{t 0}}{ }^{1.016 \delta}$..for. $\dot{\varepsilon}_{t} \quad 30 \mathrm{~s}{ }^{1}$

$2 \rho \dot{r}_{c}^{2} \frac{r_{c}}{r_{c r}} \frac{1}{4}{\frac{r_{c}}{r_{c r}}}^{4} \quad \frac{1}{3} \frac{E}{1 \mu}{\frac{r_{c}}{r_{c r}}}^{3} \quad \sigma_{t, s} \beta{\frac{r_{c}^{2} \dot{r}_{c}}{r_{c r}{ }^{3} \dot{\varepsilon}_{t 0}}}^{\frac{1}{3}} \ldots$ for. $\dot{\varepsilon}_{t}>30 \mathrm{~s}{ }^{1}$

\subsubsection{Cracked region}

In the cracked region, the circumferential stress $\sigma_{\theta} \quad$ 0, and Eq. (13) turns into

$\frac{\partial \sigma_{r}}{\partial r} \quad 2 \frac{\sigma_{r}}{r} \quad 2 \rho \dot{r}_{c}^{2} \quad \frac{r_{c}}{r^{2}} \quad \frac{r_{c}^{4}}{r^{5}}$

Integrating Eq. (24) yields the expression of the radial stress in the cracked region:

$\sigma_{r} \frac{C_{0}}{r^{2}} \quad 2 \rho \dot{r}_{c}^{2} \quad \frac{r_{c}}{r} \quad \frac{1}{4}{\frac{r_{c}}{r}}^{4}$

where $C_{0}$ is an unknown constant that needs to be solved by considering the continuous condition at $r_{c r}$, i.e. the radial stress $\sigma_{r}\left(r \quad r_{c r}\right)$ solved by Eq. (25) equals the solution of Eq. (19). Therefore, $C_{0}$ can be obtained and the radial stress in the cracked region is

$\sigma_{r} \quad 4 \rho \dot{r}_{c}^{2} \frac{r_{c}}{r_{c r}} \quad \frac{2}{3} \frac{E}{1 \mu} \frac{r_{c}}{r_{c r}}{ }^{3} \quad \frac{r_{c r}{ }^{2}}{r} \quad 2 \rho \dot{r}_{c}^{2} \quad \frac{r_{c}}{r} \quad \frac{1}{4} \frac{r_{c}}{r}{ }^{4}$

Similarly, the location of the cracked-comminuted regions interface, viz. $r_{p}$, can be determined by the boundary condition that the radial stress reaches the dynamic compressive strength $\sigma_{c, d}$ at $r_{p}$ :

$\begin{array}{llll}\sigma_{r} r r_{p} & \sigma_{c, d} r r_{p}\end{array}$

The dynamic compressive strength $\sigma_{c, d}(r \quad r p)$ can be obtained by

$\begin{array}{llllll}\sigma_{c, d} & r & r_{p} & \mathrm{DIF}_{c} r & r_{p} & \sigma_{c, s}\end{array}$ $\begin{array}{llll}\dot{\varepsilon}_{c} & \dot{\varepsilon}_{r} r r_{p} & \frac{2 r_{c}^{2} \dot{r}_{c}}{r_{p}^{3}}\end{array}$

Then $r_{p}$ is solved by:

$$
\begin{aligned}
& \frac{1}{2} \rho \dot{r}_{c}^{2}{\frac{r_{c}}{r_{p}}}^{4} \quad 4 \rho \dot{r}_{c}^{2} \frac{r_{c}}{r_{c r}} \quad \frac{2}{3} \frac{E}{1 \mu}{\frac{r_{c}}{r_{c r}}}^{3} \quad{\frac{r_{c r}}{r_{p}}}^{2} \\
& 2 \rho \dot{r}_{c}^{2} \frac{r_{c}}{r_{p}} \quad \sigma_{c, s}\left(\frac{2 r_{c}^{2} \dot{r}_{c}}{r_{p}^{3} \dot{\varepsilon}_{\mathrm{c}, 0}}\right)^{1.026 \alpha} \quad . . \text { for. } \dot{\varepsilon}_{\mathrm{c}} \quad 30 \mathrm{~s}{ }^{1} \\
& \frac{1}{2} \rho \dot{r}_{c}^{2}{\frac{r_{c}}{r_{p}}}^{4} \quad 4 \rho \dot{r}_{c}^{2} \frac{r_{c}}{r_{c r}} \quad \frac{2}{3} \frac{E}{1 \mu}{\frac{r_{c}}{r_{c r}}}^{3} \quad{\frac{r_{c r}}{r_{p}}}^{2} \\
& 2 \rho \dot{r}_{c}^{2} \frac{r_{c}}{r_{p}} \quad \sigma_{c, s}\left(\frac{2 r_{r}^{2} \dot{r}_{c}}{r_{p}^{3} \dot{\varepsilon}_{\mathrm{c}, 0}}\right)^{1 / 3} \ldots \text { for. } \dot{\varepsilon}_{\mathrm{c}}>30 \mathrm{~s}{ }^{1}
\end{aligned}
$$

\subsubsection{Comminuted region}

The UHPFRC material in the comminuted region yields according to the nonlinear Hoek-Brown criterion. Substituting Eq. (1) to the momentum conservation equation Eq. (13) with $\sigma_{1} \sigma_{r}, \sigma_{3} \sigma_{\theta}$ and replacing $\sigma_{c, s}$ by $\sigma_{c, d}$ lead to

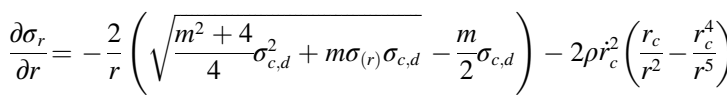

or Eq. (32) with $\mathrm{DIF}_{c}$ and strain rate further incorporated:

$$
\begin{aligned}
& \frac{\partial \sigma_{r}}{\partial r} \quad \frac{2}{r}\left(\sqrt{\frac{m^{2} 4}{4}\left(\sigma_{c, s}\right.} \frac{2 r_{c}^{2} \dot{r}_{c}}{r^{3} \dot{\varepsilon}_{\mathrm{c}, 0}}{ }^{1.026 \alpha}\right)^{2} m \sigma_{r} \sigma_{c, s} \frac{2 r_{c}^{2} \dot{r}_{c}}{r^{3} \dot{\varepsilon}_{\mathrm{c}, 0}} \\
& \\
& \frac{m}{2} \sigma_{c, s} \frac{2 r_{c}^{2} \dot{r}_{c}}{r^{3} \dot{\varepsilon}_{\mathrm{c}, 0}}
\end{aligned}
$$

$$
\begin{aligned}
& \left.\frac{\partial \sigma_{r}}{\partial r} \quad \frac{2}{r}\left(\sqrt{\frac{m^{2}}{4}\left(\sigma_{c, s} \gamma\right.} \frac{2 r_{c}^{2} \dot{r}_{c}}{r^{3} \dot{\varepsilon}_{\mathrm{c}, 0}}\right)^{\frac{1}{3}}\right)^{2} \quad m \sigma_{r} \sigma_{c, s} \gamma \frac{2 r_{c}^{2} \dot{r}_{c}}{r^{3} \dot{\varepsilon}_{\mathrm{c}, 0}} \\
& \left.\frac{m}{2} \sigma_{c, s} \gamma \frac{2 r_{c}^{2} \dot{r}_{c}}{r^{3} \dot{\varepsilon}_{\mathrm{c}, 0}}{ }^{\frac{1}{3}}\right) \quad 2 \rho \dot{r}_{c}^{2} \frac{r_{c}}{r^{2}} \quad \frac{r_{c}^{4}}{r^{5}} \quad \text { for. } \dot{\varepsilon}_{\mathrm{c}}>30 \mathrm{~s}^{1}
\end{aligned}
$$

The numerical solutions of the above nonlinear differential equations can be solved by Runge-Kutta method with Eqs. (27) and (30). Finally, the radial stress at the cavity surface $\left.\sigma_{r(r} \quad r c\right)$ can be obtained with $r \quad r_{\mathrm{c}}$ in the solutions.

\subsection{Elastic-comminuted response}

\subsubsection{Critical expansion velocity}

At a relatively high expansion velocity $\dot{r}_{c}>\dot{r}_{t}$, the cracked region diminishes and the UHPFRC target turns into an elastic-comminuted response. The critical expansion velocity $\dot{r}_{t}$ can be obtained by letting the radius of the cracked region equal to that of the comminuted region, viz. $r_{c r} \quad r_{p} r_{t}$, where $r_{t}$ is the critical radius for the response transfer.

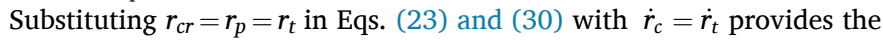
following equations:

$2 \rho \dot{r}_{t}^{2} \frac{r_{c}}{r_{t}} \frac{1}{4}{\frac{r_{c}}{r_{t}}}^{4} \quad \frac{1}{3} \frac{E}{1 \mu}{\frac{r_{c}}{r_{t}}}^{3} \quad \sigma_{t, d} r r_{t}$

where $\left.\operatorname{DIF}_{c(r} \quad r p\right)$ is calculated by Eq. (5) with 


$$
\frac{1}{2} \rho \dot{r}_{t}^{2}{\frac{r_{c}}{r_{t}}}^{4} \quad \frac{2}{3} \frac{E}{1 \mu} \frac{r_{c}}{r_{t}} \quad 2 \rho \dot{r}_{t}^{2} \frac{r_{c}}{r_{t}} \quad \sigma_{c, d} r r_{t}
$$

Solving the equations results in the solutions of the critical expansion velocity $\dot{r}_{t}$ as well as the critical radius $r_{t}$.

\subsubsection{Elastic region}

For the elastic-comminuted response, the expressions of the elastic stresses $\sigma_{r}$ and $\sigma_{\theta}$ are the same as Eqs. (19) and (20).

Similarly, the location of the elastic-comminuted region interface $r_{p}$ can be determined by substituting Eq. (19) to Eq. (27):

$\frac{2}{3} \frac{E}{1 \mu} \frac{r_{c}}{r_{p}}{ }^{3} \quad 2 \rho \dot{r}_{c}^{2}{\frac{r}{r_{p}}}_{\frac{1}{4}} \frac{r_{c}}{r_{p}} \quad \sigma_{c, s}\left(\frac{2 r_{c}^{2} \dot{r}_{c}}{r_{p}^{3} \dot{\varepsilon}_{\mathrm{c}, 0}}\right)^{1.026 \alpha} \quad \ldots$ for... $\dot{\varepsilon}_{c} \quad 30 \mathrm{~s}{ }^{1}$

$$
\frac{2}{3} \frac{E}{1 \mu} \frac{r_{c}}{r_{p}}{ }^{3} \quad 2 \rho \dot{r}_{c}^{2}{ }_{c} \frac{r_{c}}{r_{p}} \frac{1}{4} \frac{r_{c}}{r_{p}} \quad \sigma_{c, s} \gamma\left(\frac{2 r_{c}^{2} \dot{r}_{c}}{r_{p}^{3} \dot{\varepsilon}_{\mathrm{c}, 0}}\right)^{1 / 3} \quad . \text { for. } \dot{\varepsilon}_{c}>30 \mathrm{~s} \quad 1
$$

\subsubsection{Comminuted region}

In the comminuted region, the UHPFRC material yields according to the Hoek-Brown criterion. The radial stress at the cavity surface $r_{c}$ is still solved by Eq. (32) but with a different boundary condition, i.e. $r_{p}$ for the elastic-comminuted response is given by the solution of Eq. (35) rather than by that of Eq. (30), which is for the elastic-cracked-comminuted response.

The general procedure to obtain the radial stress at the cavity surface $\sigma_{r}\left(\begin{array}{rr}r & r\end{array}\right)$ is shown in Fig. 4. The required initial input parameters include $r_{c}, \quad \dot{r}_{c}, \sigma_{c, s}, \sigma_{t, s}, E, \rho, m$, where $r_{\mathrm{c}}$ equals the radius of the projectile; $\sigma_{c, s}$ and $\sigma_{t, s}$ are the static compressive and tensile strengths of the UHPFRC material, respectively; $E$ and $\rho$ are its elastic modulus and density; $m$ is obtained by Eq. (3) with $\sigma_{c, s \cdot} \dot{r}_{c}$ also represents the particle velocity ahead of the projectile and illustrates how the damage zones changes. $\dot{r}_{c}$ depends on the projectile velocity $V$ and the shape of the projectile head [24,56,57]:

$\dot{r}_{c} \quad V \cos \phi$

where $\phi$ is the angle between the axial of the projectile and the normal direction of the projectile head surface.

\section{DOP model for UHPFRC targets}

Based on the above dynamic cavity expansion theory, a model for predicting the DOP in UHPFRC target is proposed in this section. The penetration process of the projectile in a semi-infinite concrete target can be divided into two stages: a cratering stage and a following tunneling stage [19]. The cavity expansion theory is used for the tunneling stage, while the depth of the cratering stage is assumed to be $k d$, where $d$ is diameter of the projectile and $k 0.707 \quad h / d$ with $h$ being the projectile head length [14]. For simplification, only rigid projectile at normal impact is discussed in this study [19].

From Newton's second law of motion, one gets:

$$
F \quad M \frac{d V}{d t} \quad M V \frac{d V}{d x}
$$

where $F$ is the axial force on the projectile head; $M$ is the mass of the projectile. $V$ and $x$ are the projectile traveling velocity and the penetration depth at time $t$.

The axial force at the cratering stage $F_{1}$ is assumed to be proportional to the depth $x$, as suggested by the experimental deceleration data [14, 19]. Thus, the expression can be presented as [19]:

$F_{1} \quad C_{1} x$..for $x \quad k d$

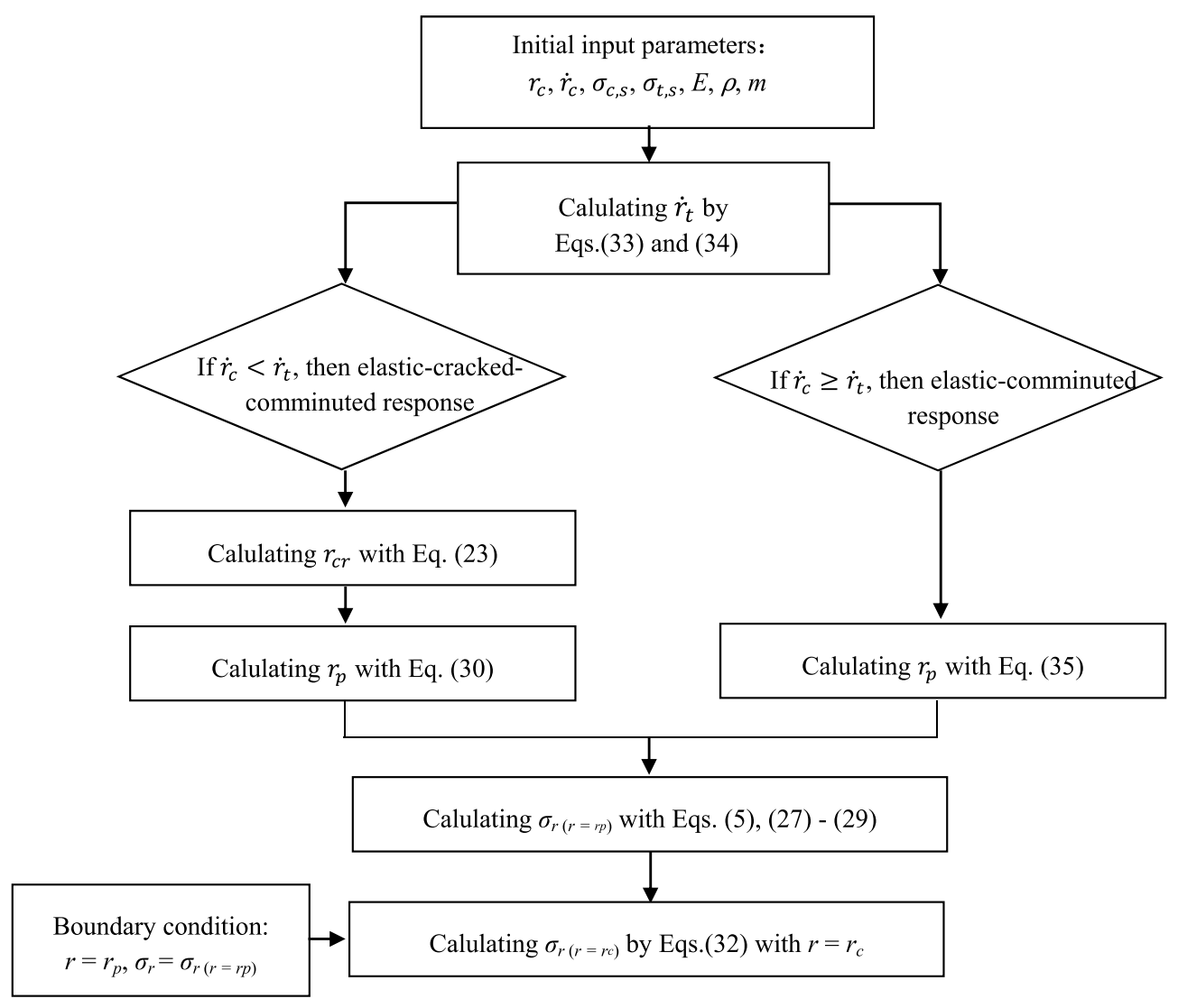

Fig. 4. Procedure to calculate the cavity surface stress. 
where $C_{1}$ is a constant.

Combining Eqs. (37) and (38), and considering the initial condition of the cratering stage: $x\left(\begin{array}{lll}t & 0\end{array}\right) \quad 0, V\left(\begin{array}{ll}t & 0\end{array}\right) \quad V_{0}$, as well as its end condition: $x\left(\begin{array}{llll}t & t_{1}\end{array}\right) \quad k d, V\left(\begin{array}{ll}t & t_{1}\end{array}\right) \quad V_{1}$ give the expression of $F_{1}$ :

$F_{1} \frac{M V_{0}^{2} V_{1}^{2}}{k d^{2}} x \ldots$ for $x \quad k d$

At the tunneling stage, the axial force on the projectile head is obtained by integrating the normal stress $\sigma_{n}$ on the projectile head surface $s$ [24]:

$F_{2} \quad \int \sigma_{n} \cos \phi d s \ldots$ for $x>k d$

In the presented model, the normal stress $\sigma_{n}$ is replaced by the

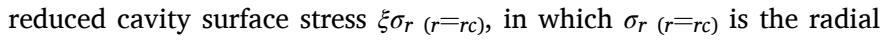
stress at the cavity surface obtained in Section 3 , and $\xi$ is a reduction factor discussed in Section 2.2. Therefore, one gets

$F_{2} \quad \int \xi \sigma_{r r} r_{c} \cos \phi d s \ldots$ for $x>k d$

To obtain the closed-form DOP formula, the numerical results from the dynamic cavity expansion model is curve-fitted with the following form as suggested by [22,23]:

$\frac{\xi \sigma_{r r} r_{c}}{\sigma_{c, s}} \quad A \quad B\left(\sqrt{\frac{\rho}{\sigma_{c, s}}} \dot{r}_{c}\right) \quad C\left(\sqrt{\frac{\rho}{\sigma_{c, s}}} \dot{r}_{c}\right)^{2}$

where the first term $A$ is the radial stress at the cavity surface under the quasi-static response [22], and it can be determined by setting $\dot{r}_{c}$

0 and DIFs 0 in the equations in Section 3. The second term in the right-hand side of Eq. (42) accounts for the rate effects, while the third term is reported to be associated with the inertia of the target $[23,58]$. The parameters $B$ and $C$ are determined by fitting the solutions of the cavity expansion model with $\sqrt{ } \rho / \sigma_{c, s} \dot{r}_{c}$ being the independent variable and $\xi \sigma_{r} r r_{c} / \sigma_{c, s}$ being the dependent variable.

Note that the parameters $A, B$ and $C$ are determined based on the theoretical solution of $\sigma_{r}(r \quad r)$ solved according to Fig. 4, i.e. with given conditions for the projectile and the target, the values of $A, B$ and $C$ can be calculated analytically. For instance, we can take the in-service $7.62 \mathrm{~mm}$ projectile and the following concrete properties as the initial inputs: $r_{\mathrm{c}} \quad d / 2 \quad 3.81 \mathrm{~mm}, \sigma_{\mathrm{ts}} \quad 13.5 \mathrm{MPa}, E \quad 46.8 \mathrm{GPa}, \rho \quad 2500 \mathrm{~kg} /$ $\mathrm{m}^{3}$, then the parameters in Eq. (42) can be determined (see Table 1). As described in Section 3, the response mode in a UHPFRC target changes with the cavity expansion velocity $\dot{r}_{c}$ higher or lower than the critical expansion velocity $\dot{r}_{t}$. Consequently, $A, B$ and $C$ also have different values under the elastic-cracked-comminuted or the elastic-comminuted mode, depending on the impact velocity and the shape of the projectile head (see Eq. (36) for the relation between the impact velocity and the cavity expansion velocity). In general, the elastic-comminuted mode yields a higher $A$ than the elastic-cracked-comminuted mode, which agrees with the trend in $[22,33]$. Moreover, it is worth mentioning that a very high impact velocity is usually required to invoke the elastic-comminuted response in UHPFRC, e.g. in the case of the $135 \mathrm{MPa}$ target against the in-service $7.62 \mathrm{~mm}$ projectile, the critical expansion

Table 1

Parameters $A, B$ and $C$ in an example.

\begin{tabular}{|c|c|c|c|c|c|c|}
\hline \multirow[t]{2}{*}{$\sigma_{\mathrm{cs}}(\mathrm{MPa})$} & \multicolumn{3}{|c|}{ Elastic-cracked-comminuted response } & \multicolumn{3}{|c|}{ Elastic-comminuted response } \\
\hline & $A$ & $B$ & C & $A$ & $B$ & C \\
\hline 105 & 11.83 & 1.05 & 4.07 & 15.48 & 0.35 & 2.91 \\
\hline 120 & 10.42 & 1.26 & 4.02 & 14.50 & 0.58 & 2.55 \\
\hline 135 & 8.89 & 2.02 & 3.49 & 12.61 & 0.83 & 2.46 \\
\hline 150 & 8.16 & 1.86 & 3.52 & 11.26 & 1.32 & 2.20 \\
\hline 165 & 7.17 & 3.39 & 2.30 & 9.92 & 1.10 & 2.35 \\
\hline
\end{tabular}

velocity $\dot{r}_{t}$ is around $402 \mathrm{~m} / \mathrm{s}$ and the corresponding critical impact velocity is more than $1400 \mathrm{~m} / \mathrm{s}$. As a result, most of the current penetration tests have impact velocities generating the elastic-cracked-comminuted response in the target, and the parameters $A, B$ and $C$ in the left side of Table 1 is more often utilized for evaluation.

Combination of Eqs. (36), (41) and (42) provides the axial force at the tunneling stage:

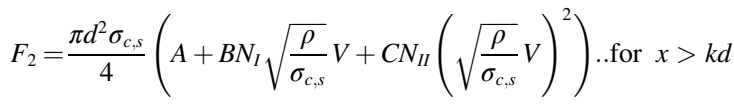

where $N_{I}$ and $N_{I I}$ are the shape coefficients of the projectile head, and their expressions are given below (see Fig. 5) [34,59]:

$N_{I} \quad \frac{8}{d^{2}} \int_{0}^{h} \frac{y y^{2}}{\sqrt{ } 1 \quad y^{2}} d x$

$N_{I I} \quad \frac{8}{d^{2}} \int_{0}^{h} \frac{y y^{3}}{1 \quad y^{2}} d x$

For an ogive-head projectile, the coefficients are [22]:

$N_{I} \frac{4 \psi \quad 1^{1.5}}{3 \psi} \frac{2 \psi 1^{2} 4 \psi \quad 1^{0.5}}{2 \psi}$
$\psi 2 \psi \quad 1 \quad \pi \quad 2 \sin ^{1} \frac{2 \psi \quad 1}{2 \psi}$

$N_{I I} \frac{8 \psi 1}{24 \psi^{2}}$

where $\psi$ is the caliber-radius-head (CRH) of the projectile.

For a conical-head projectile [34]:

$N_{I} \frac{1}{\sqrt{ } 14 \psi^{2}}$

$N_{I I} \frac{1}{14 \psi^{2}}$

where $\psi$ is the ratio between the projectile head length $h$ and the diameter $d$.

For a blunt-head projectile [34]:

$N_{I} \frac{8 \psi^{2}}{3} \quad \frac{4 \psi^{2} 1^{3 / 2}}{3 \psi}$

$N_{I I} \quad 1 \quad \frac{1}{8 \psi^{2}}$

where $\psi$ is the ratio between the sphere radius and the projectile diameter.

For a flat-head projectile, $N_{I} \quad N_{I I} 1$.

The continuous condition of the axial force at the end of the cratering stage, i.e. the beginning of the tunneling stage, requires $F_{1}\left(\begin{array}{lll}t & t_{1}\end{array}\right) \quad F_{2}$ ( $t \quad t_{1}$ ); and together with the boundary condition $x\left(\begin{array}{ll}t & t_{1}\end{array}\right) \quad k d, V$

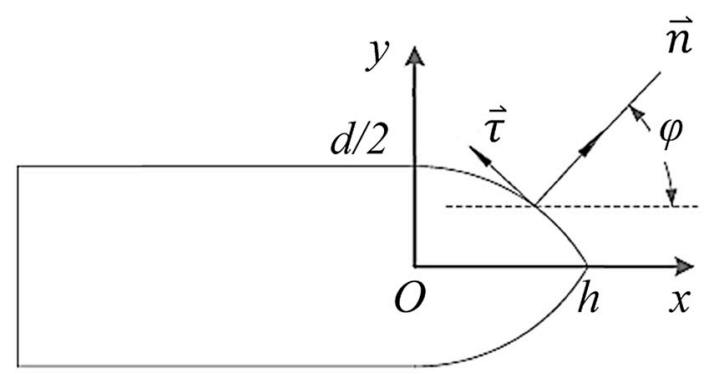

Fig. 5. Schematic of an arbitrary projectile [23]. 
$\left(\begin{array}{ll}t & t_{1}\end{array}\right) \quad V_{1}$, one obtains the initial penetration velocity at the tunneling stage $V_{1}$ :

$\frac{M V_{0}^{2} \quad V_{1}^{2}}{k d} \frac{\pi d^{2} \sigma_{c, s}}{4}\left(\begin{array}{lll}A & B N_{I} / \frac{\rho}{\sigma_{c, s}} V_{1} & \left.C N_{I I}\left(\sqrt{\frac{\rho}{\sigma_{c, s}}} V_{1}\right)^{2}\right)\end{array}\right.$

Substituting Eq. (43) into Eq. (37) yields

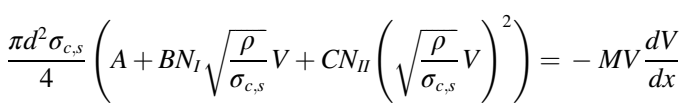

Integrating Eq. (49) and considering $x\left(\begin{array}{lllll}t & t_{1}\end{array}\right) \quad k d, V\left(\begin{array}{lll}t & t_{1}\end{array}\right) \quad V_{1}$ with $V_{1}$ solved by Eq. (48) provide the relation between $x$ and $V$. Letting $V \quad 0$ leads to the finial DOP of the projectile [29]:

DOP

$$
\begin{aligned}
& D_{I} \ln \left(1 \frac{B N_{I}}{A} \sqrt{\frac{\rho}{\sigma_{c, s}}} V_{1} \frac{C N_{I I} \rho V_{1}^{2}}{A \sigma_{c, s}}\right) \\
& 2 D_{I} D_{I I}\left(\tan { }^{1} D_{I I} \quad \tan { }^{1}\left(\frac{2 D_{I I} C N_{I I}}{B N_{I}} \sqrt{\frac{\rho}{\sigma_{c, s}}} V_{1} \quad D_{I I}\right)\right) \quad k d
\end{aligned}
$$

where $D_{I} \quad \frac{2 M}{\pi d^{2} \rho C N_{I I}}, D_{I I} \quad B N_{I} / \sqrt{4 A C N_{I I}} \quad B N_{I}^{2}$.

\section{Model validation and parameter discussion}

\subsection{Model validation}

Two groups of UHPFRC penetration test data in $[6,60]$ are taken as references for validating the proposed DOP predicting model. The quasi-static solution of the proposed model without considering the rate effects (determined by setting $\dot{r}_{c} \quad 0$ and DIFs 0 in the equations in Section 3) and the calculated DOP from the following predicting formulae are also presented and compared. The listed ACE, modified NDRC and UKAEA formulae are recommended by the US Army manual, the Air force manual and the British Army manual respectively for evaluating penetrations in concrete targets [15], and they are extensively utilized in current studies dealing with concrete penetration problems.

ACE formula [15]:

$\frac{P}{d} \frac{3.510^{4}}{\sqrt{ } \sigma_{c, s}} \frac{M}{d^{3}} d^{0.215} V_{0}^{1.5} \quad 0.5$

\section{Modified NDRC formula [15]:}

$G \quad 3.8 \quad 10 \frac{5}{d \sqrt{ } \sigma_{c, s}}{\frac{V_{0}}{d}}^{1.8}$

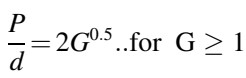

$\frac{P}{d} \quad G \quad$ 1..for $\mathrm{G}<1$

where $N^{*}$ is the head shape factor, $N^{*} \quad 0.72,0.84,1.0$ and 1.14 for flat, blunt, spherical and sharp heads, respectively.

UKAEA formula [15]:

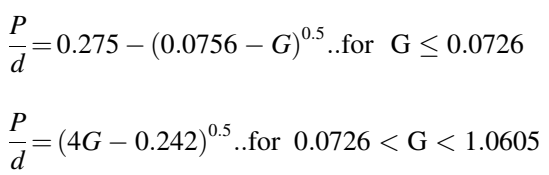

$\frac{P}{d} \quad G \quad 1 \ldots$ for $\mathrm{G} \quad 1.065$

where $G$ is the same as that given in the modified NDRC formula, viz. Eq. (52a).

Forrestal semi-empirical formula [19,61]:

$P \frac{2 M}{\pi d^{2} \rho N_{2}} \ln 1 \frac{N_{2} \rho V_{1}^{2}}{S_{f} \sigma_{c, s}} \quad 2 d$

$V_{1}^{2} \frac{2 M V_{0}^{2}}{2 M \pi d^{3} S_{f} \sigma_{c, s}}$

$S_{f} \quad 82.6 \sigma_{c, s}^{0.544}$

Li-Chen formula [14,15]:

$P \quad \frac{2 d N}{\pi} \ln \frac{1 \quad I / N}{1 \quad k \pi / 4 N} \quad k d$

$I \frac{1}{S_{l c}} \frac{M V_{0}^{2}}{d^{3} \sigma_{c, s}}$

$S_{l c} \quad 72 \sigma_{c, s}^{0.5}$

$N \quad \frac{1}{N_{I I}} \frac{M}{d^{3} \rho} \ldots$ for an ogive head projectile

\subsection{1. $135 \mathrm{MPa} U H P F R C$ target}

The penetration test results of UHPFRC targets are presented in [8]. The UHPFRC with hybrid fibers against $7.62 \mathrm{~mm}$ projectile at a velocity around $830 \mathrm{~m} / \mathrm{s}$ is chosen as an example to validate the proposed DOP predicting model. This impact velocity leads to a cavity expansion velocity around $230 \mathrm{~m} / \mathrm{s}$, which is smaller than the critical expansion velocity $\dot{r}_{t}$ of approximately $402 \mathrm{~m} / \mathrm{s}$. Therefore, the target has the elastic-cracked-comminuted response mode in this example. The input parameters are given in Table 2, in which the elastic modulus is calculated by $E \quad 8010 \sigma_{c, s}^{0.36}$ (in MPa) [62]. Based on Eq. (3), $m \quad 8.37$ can be obtained. More parameters related to the projectile can be found in [63]. From the quasi-static response of the cavity expansion model, $A \quad 8.89$ is obtained. The curve-fitting procedure for obtaining parameters $B$ and $C$ is shown in Fig. 6, and $B \quad 2.02, C \quad 3.49$ are determined.

The predicted DOP by the proposed model with the above inputs is given in Fig. 7. The experimental results, the static solution without rate effects, and the existing predicting formulae are also shown in the figure. It can be observed that the proposed model successfully predicts the DOP in the 135 MPa UHPFRC target, while the static solution results in the underestimation of the impact resistance, indicating the necessity of incorporating the rate effects in the predicting model. To be more precise, the experimentally determined DOP at $827.2 \mathrm{~m} / \mathrm{s}$ and $832.6 \mathrm{~m} / \mathrm{s}$ are around $57 \mathrm{~mm}$ and $60 \mathrm{~mm}$, respectively, which are about $3.31 \%$ lower and $0.97 \%$ higher than the predicted DOPs. The static solutions are approximately $30.2 \%$ and $25 \%$ higher than the experimental DOPs, indicating the necessity of considering the rate effects on the resistant pressure. The UKAEA formula provides results close to those of the

Table 2

Model inputs for the $135 \mathrm{MPa}$ target.

\begin{tabular}{llll}
\hline $\begin{array}{l}\text { Compressive strength } \\
\sigma_{c, s}(\mathrm{MPa})\end{array}$ & $\begin{array}{l}\text { Tensile strength } \sigma_{t}, \\
{ }_{s}(\mathrm{MPa})\end{array}$ & $\begin{array}{l}\text { Elastic modulus } E \\
(\mathrm{GPa})\end{array}$ & $\begin{array}{l}\text { Density } \rho \\
\left(\mathrm{kg} / \mathrm{m}^{3}\right)\end{array}$ \\
\hline 135 & 13.5 & 46.8 & 2500 \\
$\begin{array}{l}\text { Projectile diameter } \\
\quad(\mathrm{mm})\end{array}$ & $\begin{array}{l}\text { Projectile mass } M \\
(\mathrm{~g})\end{array}$ & Projectile $\mathrm{CRH} \psi$ & \\
7.92 & 10.5 & 5.0 & \\
\hline
\end{tabular}




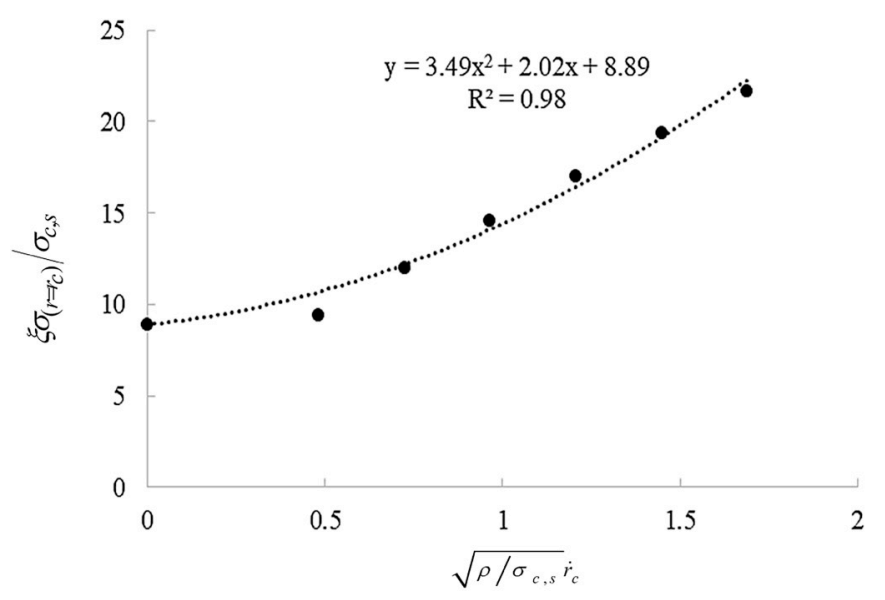

Fig. 6. Procedure to obtain $B$ and $C$.

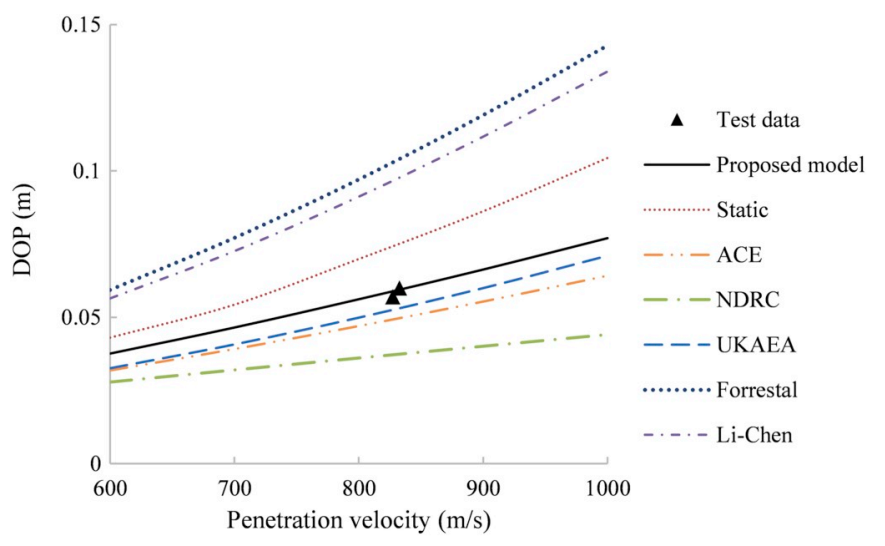

Fig. 7. Model validation of 135 MPa UHPFRC.

proposed model and the errors are around $7.89 \%$ and $11.67 \%$. Additionally, the ACE formula also gives acceptable predictions with errors smaller than $17 \%$, whereas the other formulae fail to make appropriate estimations. Both the Forrestal semi-empirical formula and the Li-Chen formula underestimate the penetration resistance of the target, i.e. the given DOPs are more than $60 \%$ higher than the experimental data. This may be attributed to the empirical constants $S$ given by Eqs. (54c) and (55c), as they are obtained by fitting the experimental data of concrete targets with relatively low strengths than UHPFRC $[19,61,64]$. On the contrary, the modified NDRC formula clearly falls beneath the experimental results, indicating overestimations of the UHPFRC resistance.

\subsection{2. $151 \mathrm{MPa}$ UHPFRC target}

To further validate the model, the experimental data of $151 \mathrm{MPa}$ UHPFRC targets impacted by a $12.6 \mathrm{~mm}$ projectile at velocities between 635 and $685 \mathrm{~m} / \mathrm{s}$ [60] are compared with the predicted results in Fig. 8. The critical expansion velocity $\dot{r}_{t}$ is about $391 \mathrm{~m} / \mathrm{s}$, i.e. the critical impact velocity to invoke the elastic-comminuted response is higher than $1200 \mathrm{~m} / \mathrm{s}$. Hence, the response of the UHPFRC target is again the elastic-cracked-comminuted mode. The relevant input parameters are given in Table 3, and $m \quad 6.61$ is calculated according to $\sigma_{c, s}$. The coefficients in Eq. (42) are determined as $A \quad 8.17, B \quad 0.83$ and $C \quad 4.30$ by applying the same curve-fitting process presented in Section 5.1.1.

In Fig. 8, a good agreement can be observed between the experimental DOPs and the predicted ones by the proposed model. The errors are in the range of $0.10 \%-5.01 \%$, except for one data at $634.2 \mathrm{~m} / \mathrm{s}$ (the error is $15.88 \%$ ), which may be attributed to the scatter of the test data. Ignoring the rate effects of the UHPFRC target leads to a smaller penetration resistance and therefore the overestimation of the DOP.

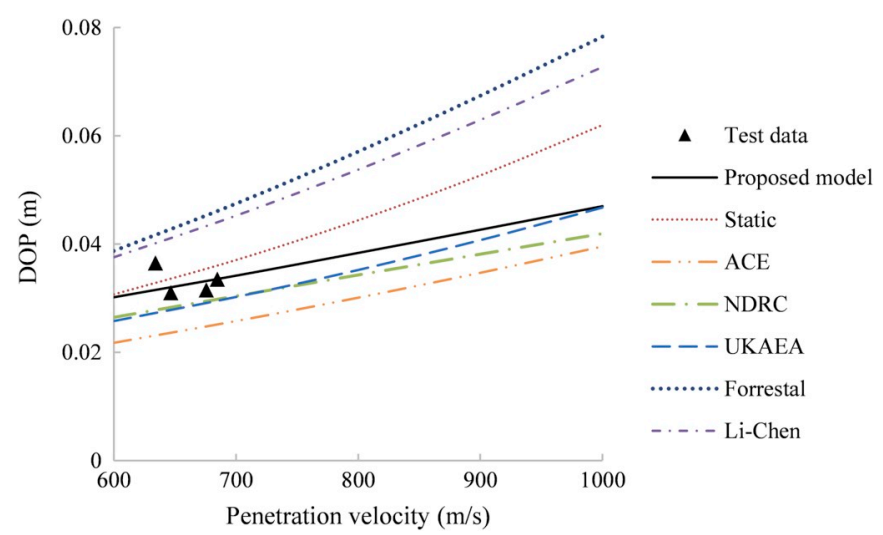

Fig. 8. Model validation of $151 \mathrm{MPa}$ UHPFRC.

Table 3

Model inputs for the $151 \mathrm{MPa}$ target.

\begin{tabular}{llll}
\hline $\begin{array}{l}\text { Compressive strength } \\
\sigma_{c, s}(\mathrm{MPa})\end{array}$ & $\begin{array}{l}\text { Tensile strength } \sigma_{t,} \\
s(\mathrm{MPa})\end{array}$ & $\begin{array}{l}\text { Elastic modulus } E \\
(\mathrm{GPa})\end{array}$ & $\begin{array}{l}\text { Density } \rho \\
\left(\mathrm{kg} / \mathrm{m}^{3}\right)\end{array}$ \\
\hline 150.9 & $\begin{array}{l}13.0 \\
\text { Projectile diameter }\end{array}$ & $\begin{array}{l}\text { Projectile mass } M \\
(\mathrm{~g})\end{array}$ & $\begin{array}{l}48.8 \\
\text { Projectile CRH } \psi\end{array}$ \\
$\quad \begin{array}{l}\mathrm{mm}) \\
12.6\end{array}$ & 15.0 & 2.5 & \\
\hline
\end{tabular}

Moreover, the overestimation is smaller than that in the previous example as the penetration velocity in this example is lower, i.e. the influences of the concrete rate sensitivity are less obvious. Furthermore, when the penetration velocity is smaller than around $800 \mathrm{~m} / \mathrm{s}$, the UKAEA formula gives a prediction similar to that of the NDRC formula, while it is getting close to the proposed model at higher velocities. The modified NDRC model presents a reasonable estimate in this example in contrast to the underestimation in the previous example in Section 5.1.1. In addition, DOPs given by the ACE formula are approximately $22 \%$ $24.5 \%$ smaller than the test results, suggesting the instability of this formulae when applied for UHPFRC targets. As with the Forrestal semiempirical formula and the Li-Chen formula, they fail again to achieve accurate results by overestimating the DOPs.

\subsection{Discussion}

The comparisons between the experimental data in Section 5.1 confirm the reliability of the proposed DOP predicting model, in this section the model is further applied to analyze the influences of the concrete strengths and the reduction factor. The experiment in Section 5.1.1 is taken as a basis, and the elastic-cracked-comminuted response mode is considered.

\subsubsection{Influences of target compressive strength}

To investigate the effects of the compressive strength $\sigma_{c, s}$, this study chooses various concrete strengths namely $75 \mathrm{MPa}, 105 \mathrm{MPa}, 135 \mathrm{MPa}$, and $165 \mathrm{MPa}$ as inputs for the proposed DOP predicting model. The corresponding Hoek-Brown parameter $m$ is calculated based on Eq. (3). The other inputs related to the target properties, e.g. the elastic modulus and the tensile strength, remain the same as those in Section 5.1.1, and the inputs for the projectile are also kept identical.

The effects of the compressive strength $\sigma_{c, s}$ on the cracked and the comminuted regions are plotted in Fig. 9. The $\mathrm{x}$-axis in the figure is the projectile velocity $V$ and it is displayed in a reverse order to show the velocity reduction in time during the penetration process. It is found that the radius of the cracked region $r_{c r}$ in the UHPFRC target increases with the decrease of the projectile velocity as the penetration process goes (Fig. 9a). In contrast, the radius of the comminuted region $r_{p}$, which suggests the area of the comminuted region, generally tends to decrease 


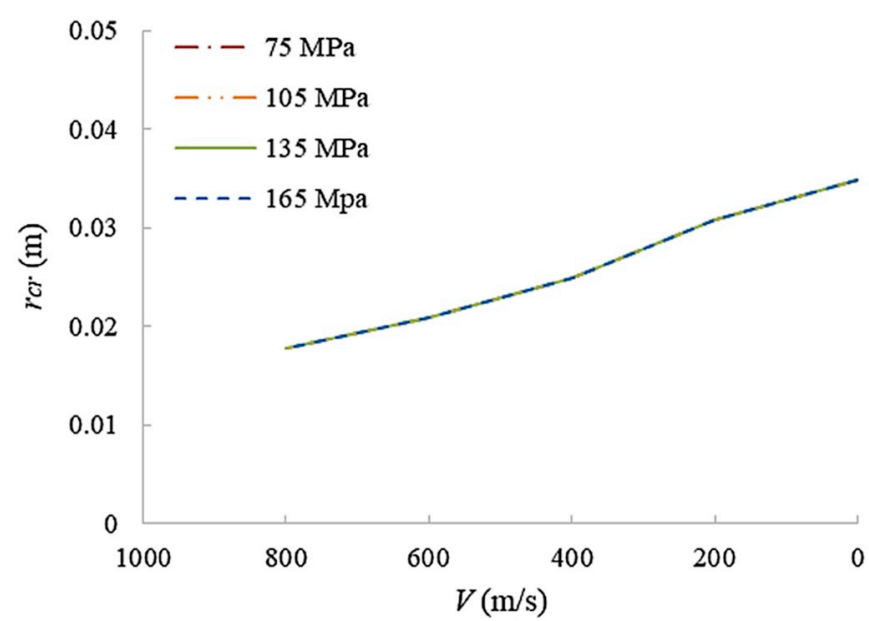

(a) $r_{c r}$

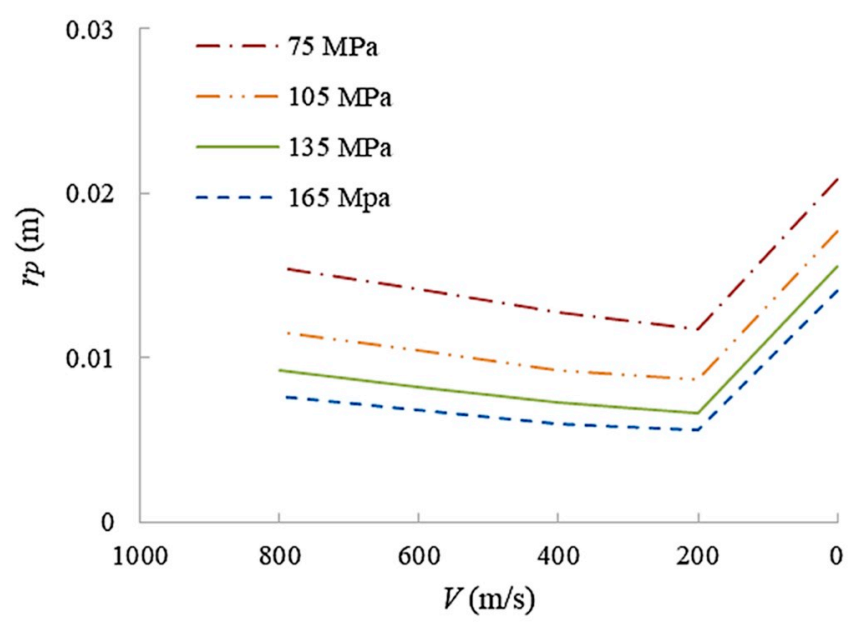

(b) $r_{p}$

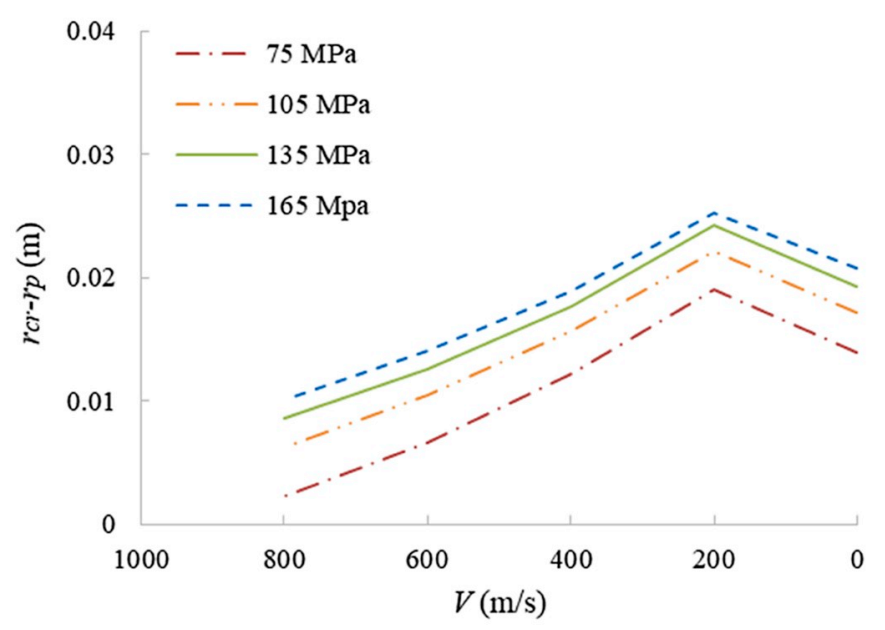

(c) $r_{c r}-r_{p}$

Fig. 9. Influence of the compressive strength on response radius. with the reduction of $V$ at dynamic conditions. An exception exists at the ballistic end $V \quad 0$, which corresponds to the quasi-static expansion $\dot{r}_{c} \quad 0$. A larger $r_{p}$ is observed when the projectile velocity approaches zero (Fig. 9b). This trend is theoretically reasonable because the static resistance is smaller than its dynamic counterpart, attributing to a larger comminuted area at $\dot{r}_{c} \quad 0$. However, this differs with the actual damage distribution in an experimental study [27] that $r_{p}$ is observed to be reduced at the ballistic end. The experimental observation is reported to be caused by the vanished concrete tangential inertial constraints at the end of the penetration process [27]. Nevertheless, since the target inertia term in Eq. (42), viz. $C \sqrt{ } \rho / \sigma_{c, s} \dot{r}_{c}{ }^{2}$, is always positive [52], the disappearance of the inertial constraints at the ballistic end cannot be reflected in the model, resulting in the different trend of $r_{p}$ at $V 0$. Moreover, the difference between $r_{c r}$ and $r_{p}$, viz. $r_{c r}-r_{p}$, can be used as an indicator to show the area of the cracked region; and it first increases gradually to a peak and then decreases with the reducing projectile velocity (Fig. 9c).

In addition, the influences of the target compressive strength on the distributions of the response zones are also revealed from Fig. 9. Firstly, the area of the comminuted region (shown by $r_{p}$ ) is smaller in the concrete target with a higher compressive strength. Secondly, the cracked region (shown by $r_{c r}-r_{p}$ ) increases with the increase of $\sigma_{c, s}$, reflecting the increasing brittleness of the higher strength concrete. Thirdly, the compressive strength of the target rarely affects the total cracking area in the target (shown by $r_{c r}$ ), agreeing with the experimental observation that target cracking is more affected by the fiber amount than the concrete strength [65]. Furthermore, the critical expansion velocity $\dot{r}_{t}$ for the target transferring from the comminuted-cracked-elastic response to the comminuted-elastic one increases with the increase of the compressive strength, while the corresponding radius of the comminuted region at the moment of transformation $r_{\mathrm{t}}$ decreases (see Fig. 10).

Fig. 11 illustrates the DOPs in the concrete targets with different compressive strength. As observed, the DOP decreases with the increase of $\sigma_{c, s}$. However, this decrease is not linear and it becomes very limited when the compressive strength reaches a threshold, in this example the value is around $105 \mathrm{MPa}$. For instance, the DOP reduction at $600 \mathrm{~m} / \mathrm{s}$ is around $6.6 \%$ when the compressive strength increases from $75 \mathrm{MPa}$ to $105 \mathrm{MPa}$, while it is about $3.3 \%$ when the target strength is improved from $135 \mathrm{MPa}$ to $165 \mathrm{MPa}$. This trend is also observed in some penetration experiments in the open literature, suggesting that the DOP no longer decreases prominently when the target strength is larger than a certain value, e.g. approximately $90 \mathrm{MPa}$ in [66] or $100 \mathrm{MPa}$ as given by [60]. Additionally, the decrease of DOP due to the compressive strength is more obvious at a higher penetrating velocity. This can be seen by comparing the slopes of the DOP curves at $600 \mathrm{~m} / \mathrm{s}$ and $900 \mathrm{~m} / \mathrm{s}$ in Fig. $11 \mathrm{~b}$. The $900 \mathrm{~m} / \mathrm{s}$ curve has a larger slope than its $600 \mathrm{~m} / \mathrm{s}$

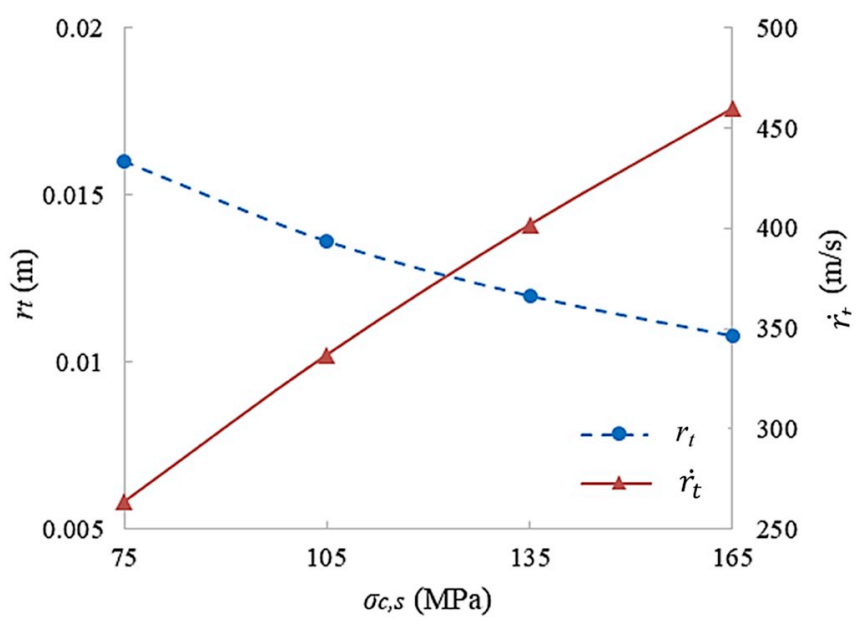

Fig. 10. Influence of the compressive strength on response transformation. 


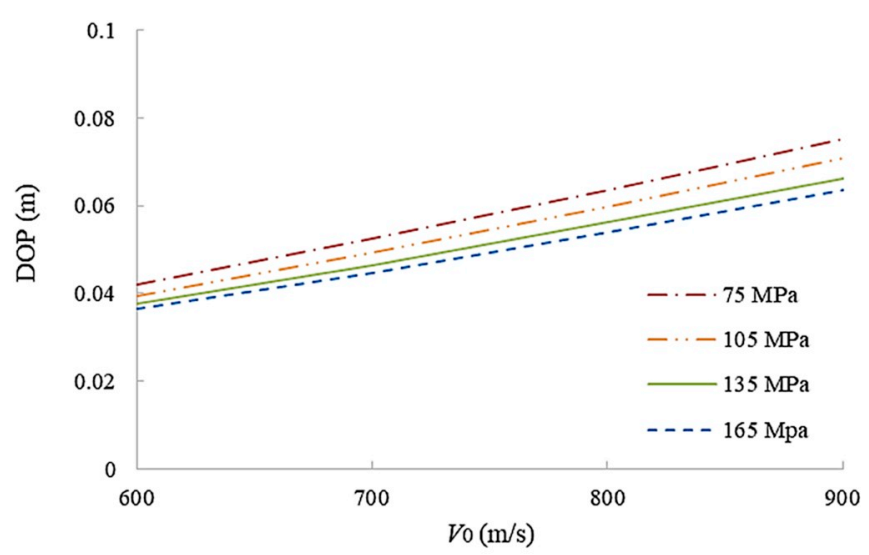

(a) DOP versus penetrating velocity

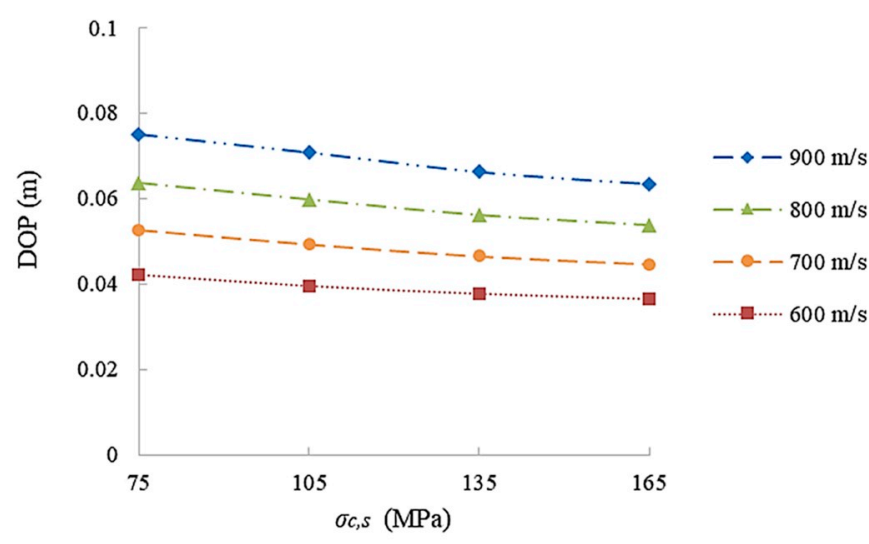

(b) DOP versus compressive strength

Fig. 11. Influence of the compressive strength on DOP.

counterpart, indicating that increasing the strength of concrete target has more prominent effects on the DOP when it is under a relatively high-velocity penetration.

\subsubsection{Influences of target tensile strength}

The effects of the concrete tensile strength are analyzed in this section with $\sigma_{t, s} \quad 7.5 \mathrm{MPa}, 10.5 \mathrm{MPa}, 13.5 \mathrm{MPa}$ and $16.5 \mathrm{MPa}$. The other input parameters related to the target and the projectile properties remain identical as those in Section 5.1.1.

Fig. 12 show the changes of $r_{c r}, r_{p}$ and $r_{c r}-r_{p}$ with the target tensile strength $\sigma_{t, s}$ and the projectile velocity $V$. Similar to the trends in Section 5.2.1, $r_{c r}$ increase with the decreasing $V$ as the penetration process approaches the end. $r_{p}$ and $r_{c r}-r_{p}$ also show similar tendencies as those in Section 5.2.1. $r_{p}$ first decreases and then increases significantly after the projectile velocity drops to a turning point near the ballistic end; whereas $r_{c r}-r_{p}$ first increases to the peak, after which it reduces remarkably. The turning points in Fig. $12 \mathrm{~b}$ and $\mathrm{c}$ indicate that there exists a projectile velocity around $V \quad 200 \mathrm{~m} / \mathrm{s}$ at which the target has a minimum comminuted region and a maximum cracked region.

In contrast to the effects of the compressive strength, the target tensile strength $\sigma_{t, s}$ has obvious influences on the total damage area $r_{c r}$ but very limited effects on the comminuted region $r_{p}$ (see Fig. 12a and b). In addition, increasing $\sigma_{t, s}$ significantly reduces the area of the cracked region $r_{c r}-r_{p}$, and the reduction is more evident at a smaller projectile velocity (Fig. 12c). Moreover, as shown in Fig. 13, the critical transforming radius $r_{t}$ seems not sensitive to the change of $\sigma_{t, s}$, whereas the critical cavity expansion velocity $\dot{r}_{t}$ decreases with the increasing $\sigma_{t, s}$. Consequently, the target with a higher tensile strength transfers from the comminuted-cracked-elastic response into the comminuted-elastic one

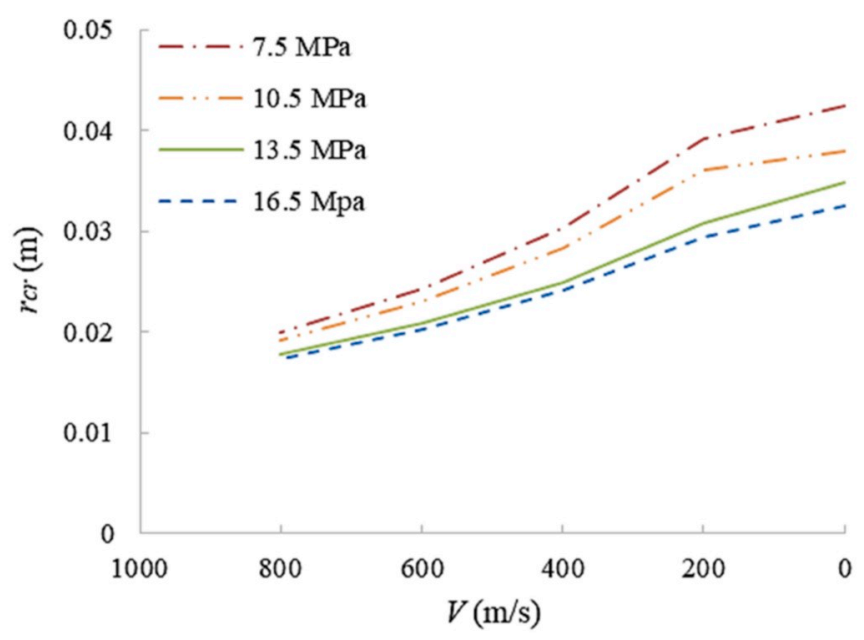

(a) $r_{c r}$

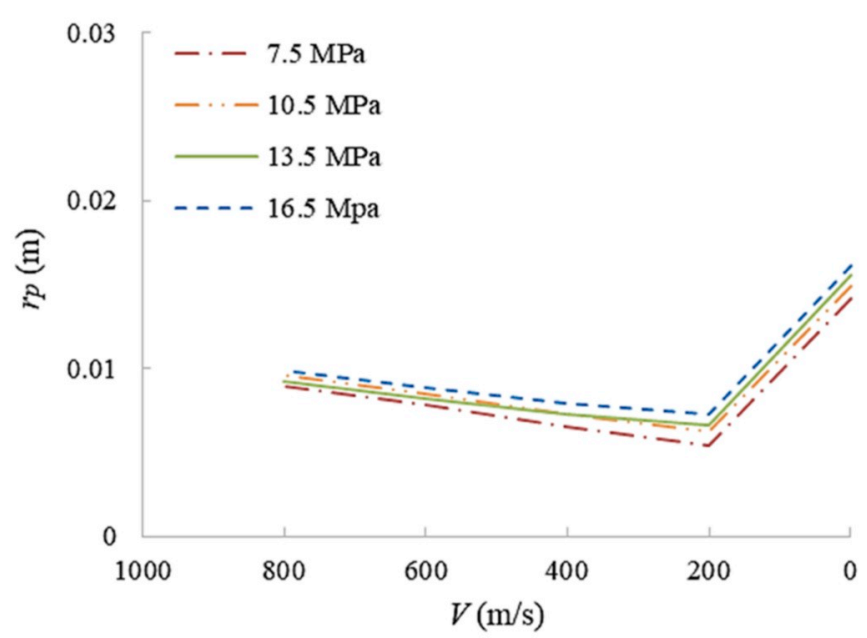

(b) $r_{p}$

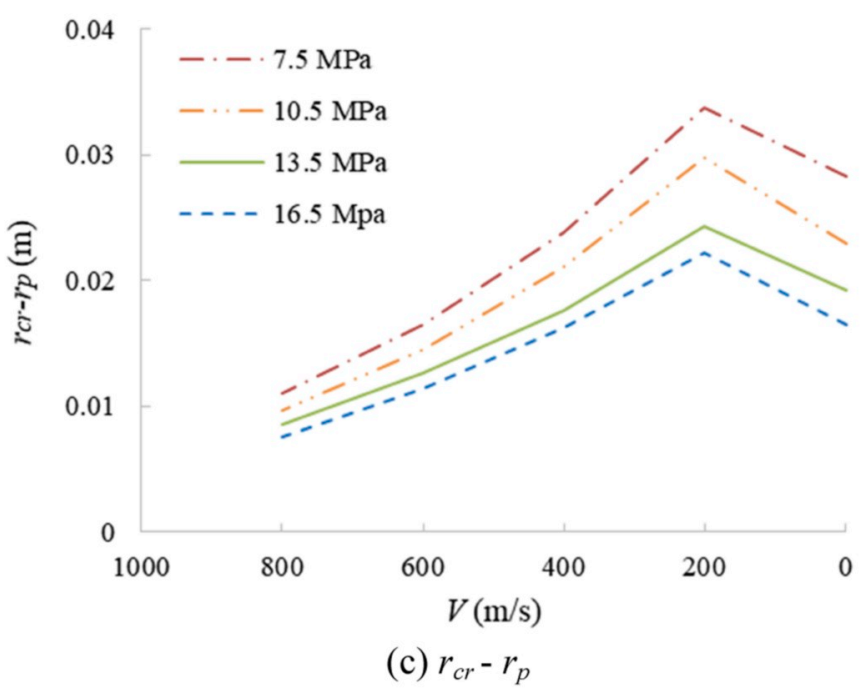

Fig. 12. Influence of the tensile strength on response radius. 


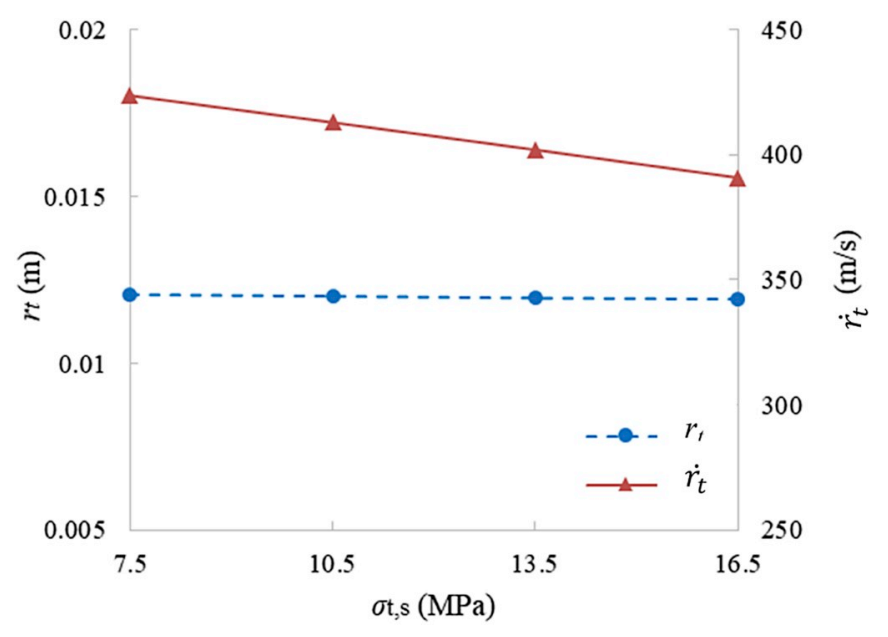

Fig. 13. Influence of the tensile strength on response transformation.

at a lower velocity, and the corresponding radius of the comminuted region at the moment of the transfer is more dependent on the target compressive strength than on its tensile strength.

The DOPs of the targets with different tensile strengths at different penetration velocities are given in Fig. 14. Insignificant reduction of the DOP is observed with the increase of $\sigma_{t, s}$, suggesting that improving the target tensile strength, e.g. by adding fibers, is not an efficient approach to reduce the DOP in the concrete target. This trend coincides with the experimental finding that increasing the fiber amount in UHPFRC has very limited contribution to the DOP although it has prominent effects on controlling the cracked area in the target surface [65]. Furthermore, taking into consideration of both Figs. $12 \mathrm{c}$ and 14, it is further noted that

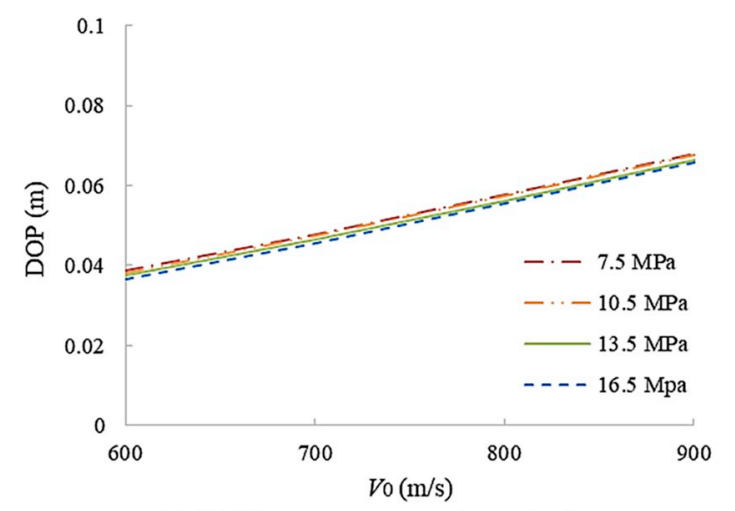

(a) DOP versus penetrating velocity

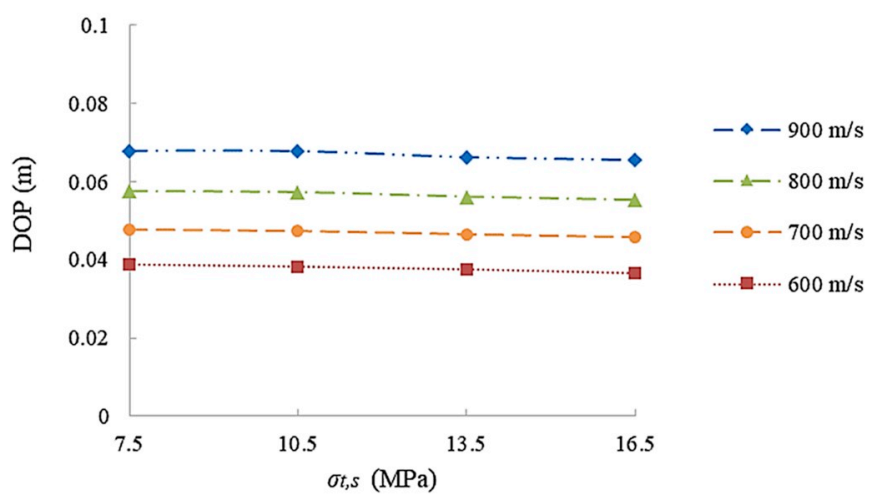

(b) DOP versus compressive strength

Fig. 14. Influence of the compressive strength on DOP. the proposed DOP predicting model may be able to reflect the effects of fibers on the UHPFRC resistance via its tensile strength $\sigma_{t, s}$, as the fibers contribute to reducing the cracked area (increasing $\sigma_{t, s}$ results in a smaller $r_{c r}-r_{p}$ in Fig. 12c) but have limited effects on the penetration depth (DOP is almost insensitive to $\sigma_{t, s}$ in Fig. 14). This may be done by establishing the relation between the fiber amount and the target tensile strength, and incorporating it into the dynamic cavity expansion model. Nevertheless, the confirmation of this point and the exact relation between the fiber amount and the DOP require more studies and will be of interests in the further research.

\subsubsection{Influences of reduction factor}

The reduction factor $\xi$ is used to correct the strength overestimation of the target due to the "artificial" rate effects given in the CEB-FIB Model Code, and its effects are analyzed to evaluate the correctness of introducing this factor. As shown in Fig. 15, $B$ increases remarkably with the increase of $\xi$ while $C$ experienced an insignificant drop. The prominent increase of $B$ with a small growth of $\xi$ shows the sensitivity of this parameter, which demonstrates the importance of choosing the reduction factor appropriately. Moreover, the dependence of $B$ on $\xi$ is in accordance with its physical meaning, i.e. $B$ is the dominate parameter reflecting the rate effects [23]. The improvement of $B$, therefore, presents the enhanced rate effects on the resistant pressure with an increasing $\xi$.

The differences between the calculated and the tested DOPs with different $\xi$ are plotted in Table 4. The calculated DOP is observed to decrease with the increase of $\xi$. This trend is reasonable because with a smaller $\xi$, the theoretical resistant pressure on the projectile $\left.\xi \sigma_{r(r r} r c\right)$ is also smaller, which consequently attributes to a larger DOP in the UHPFRC targets. When $\xi \quad 0.30$, the rate effects are over-reduced that the dynamic resistance is underestimated. Consequently, the predicted DOPs are $11.89 \%$ and $7.39 \%$ higher than the experimental data at $827.2 \mathrm{~m} / \mathrm{s}$ and $832.6 \mathrm{~m} / \mathrm{s}$, respectively. On the other hand, inaccurate DOP is obtained with an error larger than $15 \%$ when $\xi \quad 0.425$. It can be inferred that the calculated dynamic resistance would be far beyond the actual value, i.e. the DOP would be significantly underestimated, if the rate effects are fully accounted according to Eqs. (4) and (5) (with $\xi \quad 1$ ). The trend in Table 4 confirms the necessity of introducing an appropriate $\xi$ to reduce the DIFs in the CEB-FIB Model Code to achieve reasonable predictions for UHPFRC targets. The recommended range of $\xi$ is around $0.325-0.375$ for the UHPFRC targets investigated in this study.

\section{Conclusions}

The present study develops a new DOP predicting model for UHPFRC based on an improved cavity expansion theory, which accounts for the nonlinear behavior and the rate dependency of the UHPFRC material. The proposed model is validated by the experimental data and compared with previous predicting formulae. Furthermore, influences of the target compressive and tensile strengths are analyzed. The proposed DOP predicting model provides an efficient approach to design UHPFRC protective structures, and hence promotes engineering applications of the UHPFRC material in both civil and military fields. The following conclusions are drawn from the study and some directions for further research are also provided:

(1) The proposed DOP predicting model achieves a reasonable agreement with the experimental data, and it provides more accurate estimation than the currently extensively utilized predicting formulae. The UKAEA formula can give reasonable predictions, whereas the Forrestal semi-empirical formula and the Li-Chen formula tend to overestimate the DOP in the UHPFRC targets; the accuracies of the ACE formulae and the modified NDRC formulae are unstable when applied to UHPFRC. 

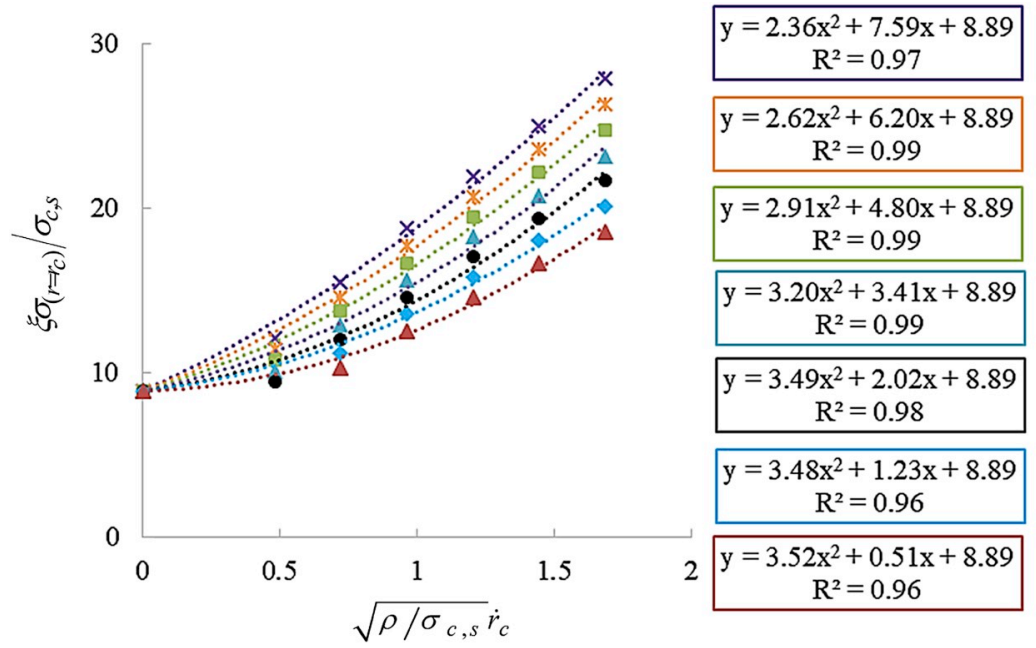

(a) Procedure to obtain $B$ and $C$

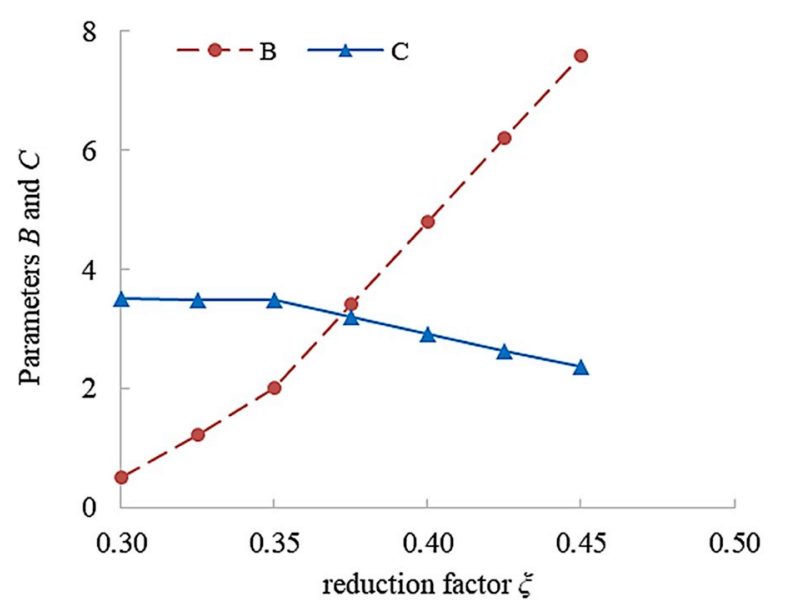

(b) $B$ and $C$ versus $\xi$

Fig. 15. Influence of the reduction factor.

Table 4

Influences of the reduction factor on the velocity and DOP.

\begin{tabular}{|c|c|c|c|c|}
\hline \multirow[t]{2}{*}{$\xi$} & \multicolumn{2}{|c|}{$V_{0} \quad 827.2 \mathrm{~m} / \mathrm{s}, P_{\text {test }}$} & \multicolumn{2}{|c|}{$V_{0} \quad 832.6 \mathrm{~m} / \mathrm{s}, P_{\text {test }}$} \\
\hline & $P_{c a l}(\mathrm{~mm})$ & $\left(P_{\text {cal }}-P_{\text {test }}\right) / P_{\text {test }}(\%)$ & $P(\mathrm{~mm})$ & $\left(P_{\text {cal }}-P_{\text {test }}\right) / P_{\text {test }}(\%)$ \\
\hline 0.300 & 63.8 & 11.89 & 64.4 & 7.39 \\
\hline 0.325 & 61.3 & 7.55 & 61.9 & 3.11 \\
\hline 0.350 & 58.9 & 3.31 & 59.4 & 0.97 \\
\hline 0.375 & 55.6 & 2.52 & 56.1 & 6.51 \\
\hline 0.400 & 52.7 & 7.50 & 53.2 & 11.40 \\
\hline 0.425 & 48.4 & 15.09 & 49.0 & 18.29 \\
\hline 0.450 & 47.9 & 15.91 & 48.4 & 19.41 \\
\hline
\end{tabular}

(2) The Hoek-Brown criterion is firstly used to describe the strength feature of UHPFRC in the comminuted region in the presented study, and an empirical equation for the dimensionless parameter $m$ is recommended. Nevertheless, more investigations on the physical meaning of $m$ would benefit the theoretical determination of its value in further studies.

(3) The inclusion of rate effects in the dynamic cavity expansion model is essential to obtain sufficient penetration resistance. However, directly using the DIF recommended in the CEB-FIP Model Code would overestimate the dynamic enhancement of the cavity surface stress, and a reduction factor is necessary to be adopted. The parameter sensitivity of the reduction factor is analyzed in the study, and more accurate predictions would be expected with more investigations on the rate effects of UHPFRC under high strain rates.

(4) The comminuted region radius $r_{p}$ and the critical transforming radius $r_{t}$ decrease with the increases of the target compressive strength $\sigma_{c, s}$ while the critical cavity expansion velocity $\dot{r}_{t}$ shows an opposite trend. A nonlinear reduction of DOP is observed with the improvement of $\sigma_{c, s}$ until it reaches around $105 \mathrm{MPa}$, higher than which the influences on DOP become very limited.

(5) Increase of the target tensile strength $\sigma_{t, s}$ results in the decreases of the cracked region area $r_{c r}-r_{p}$ as well as the critical cavity expansion velocity $\dot{r}_{t}$; Nevertheless, $\sigma_{t, s}$ has insignificant effects on the target resistance in terms of the DOP, which agrees with the experimental observations in literature that increasing the fiber amount in UHPFRC target contributes very slightly to reducing its DOP.

\section{Acknowledgment}

This research is carried out under the funding of China Scholarship Council, and Eindhoven University of Technology, and they are gratefully acknowledged for supporting this research. 


\section{References}

[1] D. Wang, C. Shi, Z. Wu, J. Xiao, Z. Huang, Z. Fang, A review on ultra high performance concrete: Part II. Hydration, microstructure and properties, Constr. Build. Mater. 96 (2015) 368-377, https://doi.org/10.1016/j. conbuildmat.2015.08.095.

[2] Z. Wu, C. Shi, W. He, Comparative study on flexural properties of ultra-high performance concrete with supplementary cementitious materials under different curing regimes, Constr. Build. Mater. 136 (2017) 307-313, https://doi.org/ 10.1016/j.conbuildmat.2017.01.052.

[3] Z. Wu, C. Shi, W. He, D. Wang, Static and dynamic compressive properties of ultrahigh performance concrete (UHPC) with hybrid steel fiber reinforcements, Cement Concr. Compos. 79 (2017) 148-157, https://doi.org/10.1016/j. cemconcomp.2017.02.010.

[4] R. Yu, P. Spiesz, H.J.H. Brouwers, Static properties and impact resistance of a green ultra-high performance hybrid fibre reinforced concrete (UHPHFRC): experiments and modeling, Constr. Build. Mater. 68 (2014) 158-171, https://doi.org/10.1016/ j.conbuildmat.2014.06.033.

[5] R. Yu, L. Van Beers, P. Spiesz, H.J.H. Brouwers, Impact resistance of a sustainable ultra-high performance fibre reinforced concrete (UHPFRC) under pendulum impact loadings, Constr. Build. Mater. 107 (2016) 203-215, https://doi.org/ 10.1016/j.conbuildmat.2015.12.157.

[6] R. Yu, P. Spiesz, H.J.H. Brouwers, Energy absorption capacity of a sustainable Ultra-High Performance Fibre Reinforced Concrete (UHPFRC) in quasi-static mode and under high velocity projectile impact, Cement Concr. Compos. 68 (2016) 109-122, https://doi.org/10.1016/j.cemconcomp.2016.02.012.

[7] P.P. Li, Q.L. Yu, Responses and post-impact properties of ultra-high performance fibre reinforced concrete under pendulum impact, Compos. Struct. 208 (2019) 806-815, https://doi.org/10.1016/j.compstruct.2018.10.071.

[8] R. Yu, Development of Sustainable Protective Ultra-high Performance Fibre Reinforced Concrete (UHPFRC), Eindhoven University of Technology, 2015.

[9] P. Maca, R. Sovjak, P. Konvalinka, Mix design of UHPFRC and its response to projectile impact, Int. J. Impact Eng. 63 (2014) 158-163, https://doi.org/10.1016/ j.ijimpeng.2013.08.003.

[10] R. Sovjak, T. Vavriník, J. Zatloukal, P. Maca, T. Micunek, M. Frydrýn, Resistance of slim UHPFRC targets to projectile impact using in-service bullets, Int. J. Impact Eng. 76 (2015) 166-177, https://doi.org/10.1016/j.ijimpeng.2014.10.002.

[11] R. Sovjak, T. Vavriník, P. Maca, J. Zatloukal, P. Konvalinka, Y. Song, Experimental investigation of ultra-high performance fiber reinforced concrete slabs subjected to deformable projectile impact, Procedia Eng. 65 (2013) 120-125, https://doi.org/ 10.1016/j.proeng.2013.09.021.

[12] J. Liu, C. Wu, Y. Su, J. Li, R. Shao, G. Chen, et al., Experimental and numerical studies of ultra-high performance concrete targets against high-velocity projectile impacts, Eng. Struct. 173 (2018) 166-179, https://doi.org/10.1016/j. engstruct.2018.06.098.

[13] J. Liu, C. Wu, X. Chen, Numerical study of ultra-high performance concrete under non-deformable projectile penetration, Constr. Build. Mater. 135 (2017) 447-458, https://doi.org/10.1016/j.conbuildmat.2016.12.216.

[14] Q.M. Li, X.W. Chen, Dimensionless formulae for penetration depth of concrete target impacted by a non-deformable projectile, Int. J. Impact Eng. 28 (2003) 93-116, https://doi.org/10.1016/S0734-743X(02)00037-4.

[15] Q.M. Li, S.R. Reid, H.M. Wen, A.R. Telford, Local impact effects of hard missiles on concrete targets, Int. J. Impact Eng. 32 (2006) 224-284, https://doi.org/10.1016/ j.ijimpeng.2005.04.005.

[16] G. Ben-Dor, A. Dubinsky, T. Elperin, Analytical engineering models for predicting high speed penetration of hard projectiles into concrete shields: a review, Int. J. Damage Mech. 24 (2015) 76-94, https://doi.org/10.1177/1056789514521647.

[17] D.Z. Yankelevsky, Resistance of a concrete target to penetration of a rigid projectile - revisited, Int. J. Impact Eng. 106 (2017) 30-43, https://doi.org/10.1016/j. ijimpeng.2017.02.021.

[18] L.H.T. NAM, High-Strength Concrete and Fiber-Reinforced Cement Composites for Protective Structures, National University of Singapore, 2017.

[19] M.J. Forrestal, B.S. Altman, J.D. Cargile, S.J. Hanchak, An empirical equation for penetration depth of ogive-nose projectiles into concrete targets, Int. J. Impact Eng. 15 (1994) 395-405.

[20] Z. Rosenberg, R. Kositski, Modeling the penetration and perforation of concrete targets by rigid projectiles, Int. J. Prot. Struct. 7 (2016) 157-178, https://doi.org/ $10.1177 / 2041419616632422$.

[21] T.L. Warren, M.J. Forrestal, Effects of strain hardening and strain-rate sensitivity on the penetration of aluminum targets with spherical-nosed rods, Int. J. Solids Struct. 35 (1998) 3737-3753, https://doi.org/10.1016/S0020-7683(97)00211-4.

[22] M.J. Forrestal, D.Y. Tzou, A spherical cavity-expansion penetration model for concrete targets, Int. J. Solids Struct. 34 (1997) 4127-4146, https://doi.org/ 10.1016/S0020-7683(97)00017-6.

[23] J. Feng, W. Li, X. Wang, M. Song, H. Ren, W. Li, Dynamic spherical cavity expansion analysis of rate-dependent concrete material with scale effect, Int. J. Impact Eng. 84 (2015) 24-37, https://doi.org/10.1016/j.ijimpeng.2015.05.005.

[24] C. Meng, Q. Tan, Z. Jiang, D. Song, F. Liu, Approximate solutions of finite dynamic spherical cavity-expansion models for penetration into elastically confined concrete targets, Int. J. Impact Eng. 114 (2018) 182-193, https://doi.org/ 10.1016/j.ijimpeng.2018.01.001.

[25] M. Zhen, Z.G. Jiang, D.Y. Song, F. Liu, Analytical solutions for finite cylindrical dynamic cavity expansion in compressible elastic-plastic materials, Appl. Math. Mech. 35 (2014) 1039-1050, https://doi.org/10.1007/s10483-014-1842-7.
[26] T.H. Almusallam, N.A. Siddiqui, R.A. Iqbal, H. Abbas, Response of hybrid-fiber reinforced concrete slabs to hard projectile impact, Int. J. Impact Eng. 58 (2013) 17-30, https://doi.org/10.1016/j.ijimpeng.2013.02.005.

[27] C. Wu, W. Li, X. Shen, W. Yao, Study of cracks in concrete target under deep penetration by a projectile, Lat. Am. J. Solid. Struct. 16 (2019) 1-13, https://doi. org/10.1590/1679-78255382.

[28] R.W. Macek, T.A. Duffey, Finite cavity expansion method for near-surface effects and layering during Earth penetration, Int. J. Impact Eng. 24 (2000) 239-258, https://doi.org/10.1016/S0734-743X(99)00156-6.

[29] M.J. Forrestal, D.Y. Tzou, A spherical cavity-expansion penetration model for concrete targets, Int. J. Solids Struct. 34 (1997) 4127-4146, https://doi.org/ 10.1016/S0020-7683(97)00017-6.

[30] M.J. Forrestal, D.Y. Tzou, E. Askari, D.B. Longcope, Penetration into ductile metal targets with rigid spherical-nose rods, Int. J. Impact Eng. 16 (1995) 699-710, https://doi.org/10.1016/0734-743X(95)00005-U.

[31] T. He, He-MingWen, X.-J. Guo, A spherical cavity expantion model for penetration of ogive-nosed projectiles into cocrete targets with shear-dilatancy, Acta Mech. 27 (2011) 1001-1012.

[32] X. Kong, Q. Fang, H. Wu, Y. Zhang, Finite spherical cavity expansion method for layering effect, Acta Mech. Solida Sin. 29 (2016) 642-654, https://doi.org/ 10.1016/S0894-9166(16)30334-2.

[33] X.Z. Kong, H. Wu, Q. Fang, G.M. Ren, Analyses of rigid projectile penetration into UHPCC target based on an improved dynamic cavity expansion model, Constr. Build. Mater. 126 (2016) 759-767, https://doi.org/10.1016/j. conbuildmat.2016.09.093.

[34] X.Z. Kong, H. Wu, Q. Fang, Y. Peng, Rigid and eroding projectile penetration into concrete targets based on an extended dynamic cavity expansion model, Int. J. Impact Eng. 100 (2017) 1339-1351, https://doi.org/10.1016/j. ijimpeng.2016.10.005.

[35] Lausanne, SwitzerlandJ. Walraven (Ed.), CEB/FIP MODEL CODE 2010, 2010th ed., the International Federation for Structural Concrete, 2010. fib.

[36] Y.Y.Y. Cao, Q.L. Yu, H.J.H. Brouwers, W. Chen, Predicting the rate effects on hooked-end fiber pullout performance from Ultra- High Performance Concrete, Cement Concr. Res. (2019), https://doi.org/10.1182/blood-2016-03-705590.

[37] E. Hoek, B. Corkum, C. Carranza-torres, B. Corkum, Hoek-Brown failure criterion 2002 Edition, in: NARMS-TAC Conf Toronto, 2002, pp. 267-273.

[38] E. Eberhardt, The Hoek-Brown failure criterion, Rock Mech. Rock Eng. 45 (2012) 981-988, https://doi.org/10.1007/s00603-012-0276-4.

[39] G.M. Ren, H. Wu, Q. Fang, J.Z. Liu, Z.M. Gong, Triaxial compressive behavior of UHPCC and applications in the projectile impact analyses, Constr. Build. Mater. 113 (2016) 1-14, https://doi.org/10.1016/j.conbuildmat.2016.02.227.

[40] Y. Farnam, M. Moosavi, M. Shekarchi, S.K. Babanajad, A. Bagherzadeh, Behaviour of slurry infiltrated fibre concrete (SIFCON) under triaxial compression, Cement Concr. Res. 40 (2010) 1571-1581, https://doi.org/10.1016/j. cemconres.2010.06.009.

[41] R. Sovjak, F. Vogel, B. Beckmann, Triaxial compressive strength of ultra high performance concrete, Acta Polytech. 53 (2013) 901-905, https://doi.org/ 10.14311/AP.2013.53.0901.

[42] J. Xie, A.E. Elwi, J.G. MacGregor, Mechanical properties of three high-strength concretes containing silica fume, ACI Mater. J. 92 (1995) 135-145.

[43] S.G. Millard, T.C.K. Molyneaux, S.J. Barnett, X. Gao, Dynamic enhancement of blast-resistant ultra high performance fibre-reinforced concrete under flexural and shear loading, Int. J. Impact Eng. 37 (2010) 405-413, https://doi.org/10.1016/j. ijimpeng.2009.09.004.

[44] N.T. Tran, T.K. Tran, D.J. Kim, High rate response of ultra-high-performance fiberreinforced concretes under direct tension, Cement Concr. Res. 69 (2015) 72-87, https://doi.org/10.1016/j.cemconres.2014.12.008.

[45] M. Hassan, K. Wille, Experimental impact analysis on ultra-high performance concrete (UHPC) for achieving stress equilibrium (SE) and constant strain rate (CSR) in Split Hopkinson pressure bar (SHPB) using pulse shaping technique, Constr. Build. Mater. 144 (2017) 747-757, https://doi.org/10.1016/j. conbuildmat.2017.03.185

[46] X. Hou, S. Cao, W. Zheng, Q. Rong, G. Li, Experimental study on dynamic compressive properties of fiber-reinforced reactive powder concrete at high strain rates, Eng. Struct. 169 (2018) 119-130, https://doi.org/10.1016/j. engstruct.2018.05.036.

[47] T. Ngo, P. Mendis, T. Krauthammer, Behavior of ultrahigh-strength prestressed concrete panels subjected to blast loading, J. Struct. Eng. 133 (2007) 1582-1590, https://doi.org/10.1061/(asce)0733-9445 (2007)133:11(1582).

[48] D.Y. Yoo, N. Banthia, Mechanical and structural behaviors of ultra-highperformance fiber-reinforced concrete subjected to impact and blast, Constr. Build. Mater. 149 (2017) 416-431, https://doi.org/10.1016/j.conbuildmat.2017.05.136.

[49] D.Y. Yoo, N. Banthia, Mechanical properties of ultra-high-performance fiberreinforced concrete: a review, Cement Concr. Compos. 73 (2016) 267-280, https://doi.org/10.1016/j.cemconcomp.2016.08.001.

[50] L. Mao, S. Barnett, D. Begg, G. Schleyer, G. Wight, Numerical simulation of ultra high performance fi bre reinforced concrete panel subjected to blast loading, Int. J. Impact Eng. 64 (2014) 91-100, https://doi.org/10.1016/j.ijimpeng.2013.10.003.

[51] R. Salgado, M. Prezzi, Computation of cavity expansion pressure and penetration resistance in sands, Int. J. Geomech. 7 (2007) 251-265, https://doi.org/10.1061/ (ASCE)1532-3641 (2007)7:4(251).

[52] M.B. Rubin, R. Kositski, Z. Rosenberg, Essential physics of target inertia in penetration problems missed by cavity expansion models, Int. J. Impact Eng. 98 (2016) 97-104, https://doi.org/10.1016/j.ijimpeng.2016.09.002.

[53] Q. Fang, X. Kong, J. Hong, H. Wu, Prediction of projectile penetration and perforation by finite cavity expansion method with the free-surface effect, Acta 
Mech. Solida Sin. 27 (2014) 597-611, https://doi.org/10.1016/S0894-9166(15) 60005-2.

[54] Y.Y.Y. Cao, Q.L. Yu, Effect of inclination angle on hooked end steel fiber pullout behavior in ultra-high performance concrete, Compos. Struct. 201 (2018) 151-160 https://doi.org/10.1016/j.compstruct.2018.06.029.

[55] Y.Y.Y. Cao, P.P. Li, H.J.H. Brouwers, M. Sluijsmans, Q.L. Yu, Enhancing flexural performance of ultra-high performance concrete by an optimized layered-structure concept, Compos. B Eng. 171 (2019) 154-165, https://doi.org/10.1016/j. compositesb.2019.04.021.

[56] B. Longcope D, M.R. Tabbara, J. Jung, Modeling of Oblique Penetration Into Geologic Targets Using Cavity Expansion Penetrator Loading With Target Free Surface Effects, 1999 vol. SAND99.

[57] M.J. FORRESTAL, V.K. LuK, Penetration into soil targets, Int. J. Impact Eng. 12 (1992) 427-444.

[58] R.S. Bornord, S.V. Hanagud, Development of a projectile penetration theory, Rep. I. Vicksburg (1975).

[59] J. Feng, W. Li, X. Wang, M. Song, H. Ren, W. Li, Dynamic spherical cavity expansion analysis of rate-dependent concrete material with scale effect, Int. J. Impact Eng. 84 (2015) 24-37, https://doi.org/10.1016/j.ijimpeng.2015.05.005.
[60] M.H. Zhang, V.P.W. Shim, G. Lu, C.W. Chew, Resistance of high-strength concrete to projectile impact, Int. J. Impact Eng. 31 (2005) 825-841, https://doi.org/ 10.1016/j.ijimpeng.2004.04.009.

[61] D.J. Frew, S.J. Hanchak, M.L. Green, M.J. Forrestal, Penetration of Concrete Targets with Ogive-Nose Steel Rods 21, 1998, pp. 489-497.

[62] A. Alsalman, C.N. Dang, G.S. Prinz, W.M. Hale, Evaluation of modulus of elasticity of ultra-high performance concrete, Constr. Build. Mater. 153 (2017) 918-928, https://doi.org/10.1016/j.conbuildmat.2017.07.158.

[63] J.K. Holmen, J.K. Solberg, O.S. Hopperstad, T. Børvik, Ballistic impact of layered and case-hardened steel plates, Int. J. Impact Eng. 110 (2017) 4-14, https://doi. org/10.1016/j.ijimpeng.2017.02.001.

[64] M.J. Forrestal, D.J. Frew, S.J. Hanchak, N.S. Brar, Penetration of grout and concrete targets with ogive-nose steel projectiles, Int. J. Impact Eng. 18 (1996) 465-476, https://doi.org/10.1016/0734-743X(95)00048-F.

[65] T.H. Almusallam, N.A. Siddiqui, R.A. Iqbal, H. Abbas, Response of hybrid-fiber reinforced concrete slabs to hard projectile impact, Int. J. Impact Eng. 58 (2013) 17-30, https://doi.org/10.1016/j.ijimpeng.2013.02.005.

[66] H. Wu, Q. Fang, X.W. Chen, Z.M. Gong, J.Z. Liu, Projectile penetration of ultra-high performance cement based composites at $510-1320 \mathrm{~m} / \mathrm{s}$, Constr. Build. Mater. 74 (2015) 188-200, https://doi.org/10.1016/j.conbuildmat.2014.10.041. 